\title{
O COMBATE À POBREZA RURAL NA AMÉRICA LATINA E OS OBJETIVOS DO DESENVOLVIMENTO SUSTENTÁVEL - A NECESSIDADE DE UM ENFOQUE RELACIONAI
}

Arilson Favareto"

\begin{abstract}
Resumo
No início do século XX, os países latino-americanos lograram expressiva redução da pobreza rural. Nos anos mais recentes, estatísticas de muitos destes mesmos países apontam arrefecimento deste desempenho positivo e, em alguns casos, uma volta mesmo do crescimento da pobreza e da fome. Mais ainda, os próximos anos serão marcados por contexto distinto daquele no qual ocorreram os avanços mencionados, com crescimento econômico modesto e maior restrição fiscal. Daí a necessidade de pensar o futuro das iniciativas de combate à pobreza rural para além da continuidade ou ampliação do que vinha sendo feito. Trata-se de situação nova, que exige inovações. Por outro lado isso se dá em um momento em que é lançada a Agenda 2030 e os Objetivos do Desenvolvimento Sustentável, ambiciosa tentativa de traçar metas em escala planetária, com o compromisso dos países em temas sociais, econômicos e ambientais. Isto pode representar uma oportunidade para novas narrativas e formas de coordenação, consistentes com uma nova geração de políticas. Este texto se estrutura em três movimentos: breve retomada da literatura sobre formas de definir pobreza, em especial pobreza rural; balanço das lições aprendidas com a trajetória recente das políticas com este fim, com ênfase na realidade latino-americana; e, por fim, uma leitura das tendências atuais e futuras do capitalismo contemporâneo e como elas impactam estas políticas e os programas na região. $\mathrm{Na}$ conclusão são apontados elementos em torno das narrativas, das estratégias de combate à pobreza e dos bloqueios à inovação na ação governamental e na cooperação internacional sobre este tema. O principal argumento é que, apesar das restrições e dificuldades, existem condições que podem ser mais bem aproveitadas no combate à pobreza rural e que um dos principais desafios é a operacionalização de uma quarta geração de políticas, agora apoiadas em um enfoque relacional, cujo conteúdo é apresentado no decorrer do texto.
\end{abstract}

Palavras-chave: Pobreza rural. Políticas Públicas. Desenvolvimento Rural. Objetivos do Desenvolvimento Sustentável.

\footnotetext{
* Sociólogo. Doutor em Ciência Ambiental pela Universidade de São Paulo (USP). Professor do Programa de Pós-Graduação em
} Planejamento e Gestão do Território da Universidade Federal do ABC (UFABC).E-mail: arilson@uol.com.br 
1 Este texto é uma versão resumida e modificada de paper produzido a pedido da Organização das Nações Unidas (ONU) para a Agricultura e Alimentação (FAO). O autor agradece os comentários e as sugestões feitos pelo corpo técnico daquela instituição embora seja, como de praxe, o único responsável pelas informações e posições aqui expressas.

\section{Introdução - o lugar das políticas de combate à pobreza nos marcos dos ODS $^{1}$}

Os Objetivos do Desenvolvimento Sustentável-acordo internacional para implementação de uma agenda sobre o tema, estruturada em torno de 17 objetivos, desdobrados em 169 metas a serem alcançadas até 2030 - representam a mais ambiciosa tentativa em curso de coordenação em torno de valores e compromissos relacionados ao bem-estar humano e à conservação ambiental. Nos marcos do documento "Transforming our world: the 2030 Agenda for Sustainable Development" (UN, 2015), busca-se unificar acordos e estratégias em desdobramento às negociações internacionais do clima e do combate à pobreza, dando seguimento ao período de implementação do Protocolo de Kyoto e dos Objetivos do Desenvolvimento do Milênio.

Apesar da enorme relevância do tema, a literatura científica sobre este instrumento é bastante incipiente. De forma esquemática, pode-se afirmar que há ao menos três posições distintas a respeito. Uma primeira, de forte ceticismo e crítica política, reúne aqueles cujos argumentos levariam a minimizar o potencial e os efeitos de acordos como os ODS, ao menos em parte porque veem limites intrínsecos aos conceitos mesmo de desenvolvimento ou de sustentabilidade. Esta literatura, todavia, polariza o diálogo com as concepções mais tradicionais sobre desenvolvimento, que o limitam ao crescimento econômico, e não com as mais recentes e promissoras teorias, segundo as quais tais noções não devem ser tomadas como modelos unívocos, mas sim como ideias cujo sentido encontra-se em disputa e, desta forma, podem se constituir em organizadoras de práticas e mobilizadoras de novas concepções sobre o futuro das sociedades e suas formas de relação com a natureza. Uma segunda posição congrega os que aderem parcialmente e pragmaticamente à retórica dos ODS, mas em uma visão antissistêmica e um tanto ingênua, na qual a soma das partes levaria naturalmente e inequivocamente ao todo. Nesta visão, a busca por alcançar as metas de cada ODS é considerada isoladamente, como se não houvesse um potencial trade-off entre alguns deles. Assim, desconsidera-se que os efeitos positivos observados em certos domínios podem vir associados à persistência ou ao agravamento dos problemas em outra das dimensões dos ODS ou no plano agregado. Por exemplo, pode-se reduzir a pobreza e a fome mas, ao mesmo tempo, aumentar os impactos ambientais quando o mais desejável seria justamente buscar um caminho que permitisse atingir estes dois ODS simultaneamente. Uma terceira posição reúne aqueles que veem na retórica do desenvolvimento sustentável uma oportunidade para melhorar as bases das interações humanas na direção de maiores níveis de bem-estar e, simultaneamente e inseparavelmente, de maior adaptabilidade 
à convivência com a biosfera em um contexto de crise social e ambiental. A consecução da oportunidade aberta com a Agenda 2030 depende de que esta terceira visão seja posta em prática. Somente assim seria possível evitar tanto o ceticismo quanto a adesão ingênua à ideia. Logo, poder-se- ia tomar os ODS como uma plataforma para a busca de convergências de esforços e um enfoque mais consistente a respeito dos desafios civilizatórios a serem enfrentados, pondo ênfase justamente em suas interdependências, e não no tratamento isolado de metas e dimensões.

Não é essa, contudo, a forma de ver que tem prevalecido em governos e em parte da comunidade científica. Nesses âmbitos, a maior parte dos esforços tem sido empenhada justamente na busca por agendas setoriais e temáticas ou para formular melhores indicadores que permitam monitorar adequadamente o progresso dos países na realização das metas acordadas. Esta é a razão pela qual uma das maiores autoridades sobre o tema, Robert Constanza - em capítulo escrito com Mans Nilsson para o relatório "Review of targets for the SDG - the Science perspective" (CONSTANZA et al., 2015) - ressalta que, para além de indicadores e monitoramento de metas isoladas, é preciso fortalecer a consistência e a efetividade da iniciativa. Para isso, elenca cinco tópicos que deveriam merecer maior atenção. Seria preciso: a) formular uma meta abrangente, que permita enfeixar e dar coerência e sentido às demais; b) desenvolver metas interligadas comuns a diferentes objetivos; c) elaborar uma nova narrativa, convincente, sobre desenvolvimento; d) agregar metas e interações; e) especificar metas. Para os autores, a grande lacuna no processo de elaboração e implementação dos ODS é a falta de uma narrativa sobre a mudança, tanto em termos de como a busca de objetivos específicos levaria a resultados mais amplos de mudança social, ou sobre como essa mudança realmente ocorre. Em outras palavras, afirmam eles, não existe um continuum claro de meios e fins; nem é claro o "fim último" dos ODS em combinação, nem tampouco se compreende como as metas e os objetivos propostos contribuiriam para alcançar esse objetivo final. A mensagem subjacente a esta perspectiva é evidente: a estratégia preconizada com a Agenda 2030 terá mais êxito se cada um dos ODS não for objeto de intervenções isoladas, e sim integradas. Para isso, é necessária a construção de uma narrativa que organize o conhecimento que se tem sobre tais problemas em uma perspectiva capaz de identificar relações de causalidade que possam estar na base de uma teoria da transição ou da mudança em direção a um estilo de desenvolvimento mais próximo do adjetivo sustentável.

Esse parece ser um aspecto que organizações com alta capacidade de incidência sobre políticas e sobre a agenda pública poderiam ou precisariam tomar como eixo organizador de suas ações. É algo também que pesquisadores deveriam ter em mente ao problematizarem temas 
associados aos ODS. O objetivo deste paper é contribuir com esta perspectiva tomando como objeto de análise justamente o ODS número 1: a erradicação da pobreza. Mais especificamente, pretende-se apresentar uma reflexão sobre como aproveitar as condições criadas pela adesão dos países lationamericanos à Agenda 2030 como oportunidade para reposicionar estratégicas de enfrentamento da pobreza rural em um marco de maior integração e coordenação de iniciativas e frentes de atuação que possam operar com a interdependência entre este e os demais ODS. A ideia central que serve de fio condutor às próximas páginas pode ser apresentada como tripla afirmação: 1) Uma estratégia para pôr fim à pobreza rural precisa ser aderente às especificidades dos contextos locais que distinguem e constituem a condição de privação de liberdades substantivas - definição cunhada por Amartya Sen sobre o que é a pobreza, hoje amplamente aceita. Para isso, é preciso posicionar tais contextos nos marcos das tendências gerais do capitalismo contemporâneo, compreender a especificidade da inserção latino-americana nos rumos desta ordem internacional e, desde estes aspectos, estabelecer marcos e diretrizes que possam dialogar com realidades de escalas menores ou mais restritas dentro de cada país; 2) No contexto latino-americano, no qual os países experimentam patamares intermediários de urbanização e de monetarização da vida social, aos temas clássicos mais relacionados à melhoria dos sistemas produtivos e da proteção social, é preciso mobilizar outros temas emergentes na literatura sobre pobreza e desenvolvimento rural. É este o caso das ocupações rurais não agrícolas, da diversidade dos modos de vida das populações rurais, das formas de acesso a mercados, das articulações entre sistemas de proteção social e de inclusão produtiva, dos sistemas de relações de trabalho, das políticas ambientais, do ordenamento territorial, entre outros; 3) As décadas recentes foram, sem dúvida, exitosas em promover uma expressiva redução da pobreza rural, ainda que não se possa afirmar o mesmo com respeito às desigualdades. De toda forma, em muitos países os indicadores disponíveis sobre pobreza mostram nos últimos anos uma perda de fôlego daquele mix de políticas que vinha sendo adotado na primeira década deste século. Pior, o contexto dos próximos anos tende a ser diferente e mais difícil para o enfrentamento da pobreza e da desigualdade. Por isso, não basta repetir ou ampliar o que vinha sendo feito. Há necessidade de atualização e reposicionamento de estratégias. Será preciso inovar para torná-las mais aderentes ao novo contexto de maior restrição fiscal, diminuição do ritmo de crescimento econômico e dificuldade em atingir o chamado núcleo duro da pobreza. Tal intuito pode ter na Agenda 2030 uma oportunidade de promoção de sinergias e complementaridades com outras políticas para além das tradicionais políticas sociais, agrícolas e agrárias. Para tanto, e este é o argumento corolário do artigo; no novo contexto, não se trata 
de meramente rearranjar temas, por agregação. Diferentemente, um novo enfoque exige mudança no ambiente institucional em torno de uma nova narrativa sobre como enfrentar a pobreza e sobre a necessidade de maior coordenação de esforços a partir dela. Isso é algo que não se resume a uma dimensão técnica. Há condicionantes políticos, sobretudo, que precisam ser explicitados. São eles que impedem que estes novos arranjos marcados por maior complexidade e complementaridade emerjam.

Para sustentar este argumento, o artigo está organizado em três seções. A primeira seção traça breve evolução da literatura sobre teorias e formas de definir e medir pobreza. A segunda retoma a trajetória das políticas de combate à pobreza rural ao longo do tempo, com ênfase para a experiência latino-americana recente, destacando os resultados alcançados e os principais ensinamentos obtidos. A terceira seção apresenta elementos do novo contexto do capitalismo contemporâneo, as tendências que se projetam para a América Latina, e como elas impactam a luta contra a pobreza. Nas conclusões, são recuperadas as principais afirmações das seções anteriores em diálogo com o tema geral da busca por novas narrativas sobre a pobreza rural e sobre as formas de enfrentá-la.

\section{Brevíssima nota sobre a evolução das teorias e formas de definição da pobreza}

Esta primeira seção apresenta um resumo esquemático da literatura sobre teorias e formas de definir e de medir a pobreza, organizado em três momentos sucessivos. Um primeiro momento em que predominaram abordagens unidimensionais, com destaque para a privação de renda como parâmetro fundamental de definição da pobreza, e tendo as chamadas linhas de pobreza monetária como forma de mensuração amplamente adotada. Um segundo momento surge com os enfoques embasados em aspectos multidimensionais, dos quais os índices de necessidades básicas insatisfeitas são clara expressão. E um terceiro momento quando há a ascensão de abordagens e teorias baseadas em um enfoque relacional, segundo as quais, para além de medidas padronizadas, contextos e modos de vida são decisivos para se compreender possibilidades e bloqueios à superação das condições de privação. Como será demonstrado, embora estejamos atualmente na terceira etapa desta trajetória, as políticas públicas ainda são orientadas predominantemente por elementos coerentes com a primeira etapa mencionada, como se observa pela ênfase dada às transferências condicionadas de renda, que muitas vezes têm precedência sobre aspectos enfatizados na segunda etapa, marcada pela ideia de multidimensionalidade, e quase nunca alcançam os elementos enfatizados pela terceira etapa, marcada pelo enfoque relacional. 
A primeira geração de maneiras de definir e medir a pobreza deu forma à abordagem mais conhecida e ainda hoje amplamente utilizada, segundo a qual pobreza se define pela ausência de renda mínima. Originada no final do século XIX (GEORGE, 1879; BOOTH, 1889/1991; ROWNTREE, 1901) e usada principalmente no século XX, essa visão se baseia em duas razões subjacentes: a ideia de que a pobreza é definida pela ausência de um valor mínimo necessário para realizar uma vida digna; e, por extensão, como as sociedades modernas passam por processo crescente de monetização da vida social, o mais importante seria garantir a todos um mínimo de renda monetária. Com isso famílias pobres poderiam escapar de privações básicas ao terem meios para acessar, nas várias esferas de suas vidas, recursos e serviços necessários à satisfação do que seria fundamental ao seu bemestar. A expressão dessa concepção em termos normativos se encontra na definição das chamadas "linhas de pobreza" (WORLD BANK, 2007): a identificação da quantidade mínima de renda monetária abaixo da qual uma pessoa seria considerada pobre e a consequente necessidade de que sejam providos meios para superá-la. Em alguns estudos, argumentou-se que esses montantes mínimos exigidos poderiam ser calculados por outras medidas distintas da dimensão meramente monetária, por exemplo, em termos de calorias consumidas. No entanto, ao longo do tempo e com o avanço das abordagens economicistas, a renda monetária foi amplamente adotada como principal variável a ser operada.

No último terço do século passado e mais claramente a partir da década de 1990, esse conceito foi questionado por evidências, teorias e autores que se tornaram clássicos. Embora não tenha sido o primeiro, o caso mais conhecido é a obra do Prêmio Nobel em Ciências Econômicas, Amartya Sen. Em alguns de seus principais livros (SEN, 1982, 1992, 1998), Amartya Sen apresentou três argumentos contra a ideia de pobreza como ausência de renda mínima. O primeiro é que nem tudo poderia ser traduzido em termos monetários. Entre agricultores, por exemplo, a produção para autoconsumo, não comercializada e, portanto, não traduzida em ganhos monetários, é fator importante de segurança alimentar e, consequentemente, de saúde e o bem-estar. O segundo aspecto é que o nível mínimo necessário para escapar da privação é algo que varia muito no espaço, no tempo, e em diferentes culturas, algo que as linhas de pobreza monetária deixam escapar. O terceiro aspecto diz respeito aos conflitos entre dimensões que as pessoas podem valorizar para seu bem-estar, já que, existindo uma diversidade de seres humanos, com distintos valores e visões de mundo, são também diversos os critérios para avaliar o que é uma condição de bem-estar e para sentir-se nesta condição. 


\section{A abordagem multidimensional da pobreza}

Esta crítica à visão unidimensional da pobreza baseada em ausência de um mínimo de renda foi traduzida em uma definição mais ampla: a ideia de privação da capacidade de os indivíduos fazerem escolhas a partir das coisas que consideram importantes para seu bem-estar, de acordo com suas concepções de mundo e de vida. Esta é a essência da "abordagem das capacitações” (capabilities approach), formulada pelo próprio Sen (1998) e Nussbaum (2006). Ela considera que, entre seres humanos, existe uma diversidade de concepções e valores do que se deve buscar como objetivo e que dá sentido à existência individual. Em outras palavras, significa que todo ser humano e todo grupo social pode valorizar diferentes tipos de "realizações". Alguns podem preferir uma vida longa, segura e saudável, de forma coerente com as tradições de alguns povos; outros, a expansão de possibilidades materiais para seus descendentes, mesmo que isso implique riscos e vulnerabilidades no momento atual. Dependendo das escolhas feitas em relação às conquistas desejadas, certos "funcionamentos" são mais importantes do que outros - ter uma vida saudável ou viver em comunhão com a natureza pode ser um funcionamento valorizado entre algumas comunidades; de forma diferente, expandir as possibilidades materiais ou o uso de tecnologias artificializadas pode ser um funcionamento privilegiado em outras. E, finalmente, certos "funcionamentos" exigem certos tipos de "capacidades" - renda para alguns, autonomia, melhor saúde ou boa educação para outros. Com a combinação destes três conceitos realizações, funcionalidades e capacidades (achievements, functionings, capabilities) - seria possível chegar a medidas de pobreza e a instrumentos para enfrentá-la que sejam mais coerentes com a diversidade dos seres humanos e suas motivações. Uma ideia bastante sedutora, ainda que de difícil operacionalização.

A contribuição da abordagem de capacidades influenciou a adoção do que é convencionalmente chamado de "abordagem multidimensional" para a pobreza, um fenômeno visto como algo que: a) envolve várias dimensões e não somente renda; b) não pode ser considerado em termos absolutos, mas sim em termos relativos à história e ao contexto de cada grupo social ou indivíduo; c) envolve também distribuição desigual de oportunidades que estes mesmos grupos sociais ou indivíduos precisam acessar para satisfazer seu bem-estar. Em outras palavras, importam decisivamente, as múltiplas dimensões, os contextos, e as desigualdades em cada contexto. O problema é como operar com a diversidade embutida neste conjunto de conceitos. Se, por um lado, cada grupo social ou mesmo cada indivíduo pode apreciar diferentes dimensões de sua própria existência, por outro seria possível identificar uma série de "liberdades substantivas e fundamentais" (SEN, 
1998) às quais todos os indivíduos deveriam ter acesso, independentemente de especificidades contextuais, para fazer escolhas básicas. São elas: ter uma renda mínima, algo importante em sociedades crescentemente marcadas pela monetização da vida social; saber ler e interpretar a realidade para poder nela se posicionar, o que é mais amplo do que o simples acesso à educação; fugir da morbidade precoce, o que envolve condições básicas como superar a fome e a desnutrição, mas também viver em condições sanitárias adequadas e protegido de formas de violência contra a pessoa; participar das decisões de sua comunidade, o que é mais do que o simples direito de votar; e finalmente usufruir de um meio ambiente saudável (SEN, 1999, 2007).

O Índice de Desenvolvimento Humano (IDH), amplamente conhecido e adotado como medida de desenvolvimento que valoriza o bem-estar (UNDP, 1998) foi criado em explícito e declarado diálogo com essa ideia. $\mathrm{O}$ índice busca sintetizar três dessas dimensões fundamentais: renda, educação e saúde. O IDH foi reconhecido como progresso em termos de medição do desenvolvimento quando comparado, por exemplo, com o Produto Interno Bruto (PIB). Mas alguns problemas permaneceram sem solução. O prefácio de Sen para a primeira edição do Relatório de Desenvolvimento Humano traz alerta sobre esses limites: dimensões importantes, como civilidade, foram omitidas devido à dificuldade de encontrar boas estatísticas para medi-la; o cálculo de médias que envolvem diferentes aspectos, como renda e educação, tende a levar a graves distorções; e sintetizar todos esses elementos em um único ranking também pode levar a mal-entendidos, quando seria preferível apresentar os diferentes perfis de desenvolvimento ou tipologias, por exemplo, comparando e contrastando o desempenho dos países em diferentes dimensões - uma melhoria da renda pode ser acompanhada de desempenho satisfatório em relação a indicadores de educação e saúde, o que contrasta com situações em que, apesar dos avanços na dimensão econômica, persistem problemas sociais; resta evidente que as consequências disto para políticas públicas são diferentes em cada situação. Além disso, o IDH nada diz sobre a dimensão ambiental.

Em outro terreno desse mesmo debate, especificamente em consonância com a ideia de privação de liberdades substantivas ou fundamentais, países e agências internacionais passaram a adotar indicadores multidimensionais não só para monitorar o desenvolvimento mas também - e especificamente - para projetar políticas de redução da pobreza. Uma das expressões mais bem conhecidas desses esforços é o Índice de Necessidades Básicas Insatisfeitas (INBI) (FERES; MANCERO, 2001), que calcula, para determinado local, o contingente de população sem acesso a um conjunto de bens e serviços nas dimensões fundamentais do 
bem-estar humano básico. A grande vantagem de ferramentas como essa, em comparação com a primeira geração de indicadores e políticas, é que elas permitem operar com uma definição de pobreza que a retrata como um fenômeno multidimensional. No entanto, é novamente necessário identificar limitações. A principal está na definição relativamente arbitrária das linhas de corte a partir da qual se considera que determinada necessidade está ou não satisfeita. Consequentemente, a pobreza, embora compreendida de forma multidimensional, acaba sendo definida em termos absolutos e não relativos.

\section{Os achados da Comissão Stiglitz/Sen/Fitoussi e as bases para um enfoque relacional}

As dificuldades que envolvem definição e medição da pobreza também ocorrem em outras áreas correlatas, como desempenho econômico e sustentabilidade. Além disso, a literatura disponível sobre desenvolvimento e bem-estar vem crescentemente chamando a atenção para as interdependências entre essas dimensões: certos estilos de crescimento econômico podem favorecer inclusão social ou conservação ambiental, enquanto outros podem levar ao crescimento com deterioração das demais dimensões. Para fornecer soluções para esses problemas, no início deste século o governo francês promoveu a constituição da Comissão para a Mensuração da Performance Econômica e do Progresso Social (CMEPSP), também conhecida como Comissão Stiglitz-Sen-Fitoussi (CMEPSP, 2012). Há várias recomendações reunidas no relatório final do CMEPSP. De forma esquemática, e considerando especificamente o que diz respeito à dimensão social, os resultados e as recomendações podem ser resumidos como segue. Consideradas em seu conjunto, estas recomendações permitem operar com uma concepção relacional ou interdependente da pobreza. Afirmam os autores que:

- didas subjetivas do bem-estar fornecem informações importantes sobre a qualidade de vida. Portanto, seria preciso considerar avaliações que as pessoas fazem de suas próprias vidas e prioridades.

- Qualidade de vida também depende de condições e oportunidades objetivas. Por isso, é necessário melhorar e monitorar oito dimensõeschave: saúde, educação, atividades pessoais, voz política, conexões sociais, condições ambientais, insegurança social e insegurança econômica.

- Desigualdades são relevantes e devem ser avaliadas de forma abrangente para as oito dimensões mencionadas.

- Pesquisas devem ser conduzidas para avaliar interdependências e vínculos entre essas dimensões, especialmente visando ao desenho, à implementação e à coordenação de políticas em cada área. 
- Instituições estatísticas devem fornecer informações sobre as distintas dimensões mencionadas da qualidade de vida, permitindo a construção de diferentes e combinados índices sintéticos ou tipologias que possam subsidiar a formulação, a implementação e o monitoramento de políticas.

- Os mínimos a serem garantidos em cada dimensão e as prioridades a serem estabelecidas no tratamento a ser dado a cada dimensão precisam resultar de algum tipo de contratualização em cada sociedade, em vez de se apoiarem em decisões arbitrárias ou puramente tecnocráticas (CMEPSP, 2012).

Essas considerações ampliam o leque de dimensões e formas de ver a pobreza como superação das privações básicas a partir de um mínimo determinado, e põem ênfase nas interdependências entre dimensões em que estas privações se apresentam e nas escolhas que é preciso fazer em torno delas. Esta é a contribuição central do relatório e a principal inovação perante formas anteriores de conceber o que é pobreza e os meios de enfrentá-la. Aqui reside também a conexão possível e potencial entre o tratamento específico da pobreza e o desafio posto pela Agenda 2030 e pelos ODS: a necessidade de olhar para o conjunto de dimensões sob uma perspectiva relacional e interdependente - isto é, envolve relações e causações recíprocas entre dimensões e, também, relações entre indivíduos e grupos sociais e seu contexto. Antes de discutir a operacionalização desta ideia, entretanto, é importante abordar outro tema: a especificidade da pobreza no contexto das áreas rurais. A isto é dedicado o próximo tópico.

\section{As especificidades da pobreza rural nos marcos de um enfoque multidimensional e relacional}

Dois aspectos fundamentais distinguem as condições dos pobres rurais daquelas vivenciadas pelos habitantes das áreas urbanas. Primeiro, um dos aspectos é o fato de parte expressiva das populações rurais pobres não participar integralmente de mercados (não só os mercados de produtos agrícolas mas também mercados de trabalho ou mercados de bens e serviços). Quando esse tipo de participação ocorre, muitas vezes envolve o que a literatura chama de mercados incompletos e imperfeitos (ELLIS, 1991). Muitos desses pobres rurais são camponeses, agricultores familiares e populações tradicionais. Por um lado, isso implica certo grau de flexibilidade e autonomia nas formas de gestão do trabalho e no uso de recursos naturais. Por outro lado, as restrições materiais são onerosas para essa população, tornando a liberdade e a autonomia relativas severamente limitadas ou acompanhadas de privação básica e severa. Consistente com esta condição, 
entre a população rural o principal objetivo na organização de estratégias de vida é a "reprodução social do grupo familiar" (LAMARCHE, 2003). Como legado de um ethos camponês, e em contraste com populações urbanas nas sociedades industriais, a população rural tende a usar essa autonomia relativa para combinar todas as possibilidades disponíveis para superar as limitações de privação, isolamento e escassez que marcam sua história. Isso envolve autoconsumo e comercialização, migração e permanência, trabalho assalariado temporário ou parcial e trabalho no estabelecimento familiar, formas alternativas de financiamento e poupança.

A diversidade de maneiras pelas quais essas estratégias familiares de reprodução social podem se concretizar deu origem ao conceito de "modos de vida" (rural livelihoods). De acordo com Ellis (1991, p. 17), um modo de vida é definido como "[...] as atividades, os ativos e os acessos que determinam, em conjunto, a vida de um indivíduo ou grupo familiar". Para o mesmo autor, a diversificação dos modos de vida, vista como elemento fundamental nos marcos das estratégias de reprodução social destes grupos, é definida como “[...] o processo pelo qual as famílias constroem um portfólio diversificado de atividades e capacidades de suporte à sobrevivência e à melhoria de seu padrão de vida" (ELLIS, 1991, p. 17). Do mesmo modo, Scoones (1998, p.3) questiona que a principal questão relacionada à compreensão dos modos de vida, acrescida do adjetivo sustentáveis (sustainable rural liveliboods), é:

[...] dado um contexto particular (de condições políticas, históricas, agroecológicas e socioeconômicas), que combinação de recursos (livelihood resources - ou diferentes tipos de capital) resultam na habilidade de buscar quais estratégias de vida (livelihood strategies - ou intensificação/extensificação agrícola, diversificação, migração) com que resultados?.

Nesse contexto, é atribuída importância particular a processos institucionais, envolvendo instituições e organizações formais e informais, que influenciam a capacidade de realização dessas estratégias e de obtenção destes resultados.

Essa diversidade de possíveis arranjos feitos pelas famílias rurais para viabilizar seus modos de vida e o trade-off aí contido levam ao seguinte ponto: é impossível abordar interdependências entre decisões tomadas pelas famílias, como sugere o conceito de modos de vida, se a dinâmica responsável pela produção de privação for considerada de forma fragmentada ou isolando aspectos que, na vida social e nas formas de concepção de mundo das famílias rurais pobres, aparecem conectadas e interdependentes. Em outras palavras, é necessário evitar três dicotomias comuns nas narrativas sobre pobreza e desenvolvimento rural operadas tanto pelo mundo acadêmico como por formuladores e gestores de políticas: 
aquela que envolve fontes de renda, separando rendas agrícolas e rendas obtidas fora do estabelecimento agrícola; a dicotomia entre rendimentos monetários e não monetários; e a separação entre processos relativos à dimensão socioeconômica e a dimensão ecológica de que dependem estes sistemas sociais e modos de vida. Em vez disso, é necessário levar em consideração as diferentes possibilidades de combinação desses elementos.

Segundo aspecto que distingue as populações rurais e, em especial, as populações rurais pobres: elas geralmente vivem em assentamentos mais dispersos e longe da infraestrutura urbana, o que muitas vezes significa acesso difícil aos equipamentos sociais necessários para superar privações, como bons hospitais, redes adequadas de saneamento, estabelecimentos de ensino médio e superior. Muitas regiões rurais dependem, para isso, de vínculos com centros urbanos próximos ou distantes. Portanto, é necessário não apenas considerar os aspectos individuais da pobreza, ou mesmo os internos a um estabelecimento agropecuário. É preciso adotar uma escala capaz de capturar os links entre áreas rurais e as cidades das quais dependem para acessar mercados e serviços.

De forma coerente com argumentos desse tipo, alguns autores, como Abramovay (2003) e Berdegué e Schejtman (2003), entre outros, consideraram a "abordagem territorial" uma inovação importante nos estudos rurais no final do século XX por pelo menos três razões principais. Este enfoque, em especial a ideia de "território", implicaria: a) a adoção de uma perspectiva intersetorial, uma vez que as famílias rurais usam cada vez mais combinações de rendimentos provenientes da agricultura, indústria e setores de serviços; b) uma ênfase na complementaridade entre espaços rurais e urbanos, evitando uma dicotomia artificial que os modos de vida rompem cotidianamente com a mobilidade pendular entre o rural e o urbano; c) a identificação da inevitável interdependência entre sistemas sociais e ecológicos contida na ideia de território, algo geralmente separado pela literatura especializada em ciências biológicas e sociais.

Do mesmo modo, ao realçar a importância do enfoque territorial para a trajetória dos estudos e das políticas para as áreas rurais, Favareto (2007) argumenta que o conteúdo da vida rural na virada do século XXI se apresenta como uma nova etapa na história de longo prazo destes espaços. Nela, em vez de desaparecerem ou diminuírem inexoravelmente - como preconizado por muitos no auge da sociedade industrial -, as áreas rurais estariam cada vez mais integradas à dinâmica mais ampla dos processos de desenvolvimento, justamente pela unificação de diferentes mercados famílias rurais agora mesclam suas fontes de renda obtidas na produção agrícola com aquelas obtidas em centros urbanos próximos, unificando mercados de trabalho antes isolados; bens e serviços antes restritos às zonas urbanas agora são acessados também por populações rurais, unificando 
mercados de consumo antes mais apartados; e mesmo bens simbólicos agora são partilhados entre os dois espaços como é o caso da busca por amenidades naturais e amenidades urbanas por populações de residentes nas duas áreas, ou a aproximação de hábitos de consumo de populações rurais em relação àqueles experimentados por populações urbanas, havendo uma unificação do mercado de bens simbólicos, como o chamaria Pierre Bourdieu.

Ainda em Favareto (2007), afirma-se que, nesta nova etapa, há uma mudança qualitativa no conteúdo social das três dimensões que definem o que é o rural. No que diz respeito à proximidade entre sociedade e natureza, primeira característica distintiva da vida rural, ocorre nos tempos atuais uma mudança qualitativa nas formas de uso social dos recursos naturais. Se antes o uso desses recursos se voltava quase exclusivamente à produção de bens primários, alimentos em especial, hoje há crescente diversificação de possibilidades de uso destes recursos, entre as quais aquelas relacionadas à valorização de amenidades naturais, conservação da paisagem e da biodiversidade, ou à produção de fontes de energia renováveis. As relações interpessoais de proximidade, segunda característica típica da vida rural, também estão sujeitas a uma mudança fundamental: a homogeneidade relativa e o apego à tradição que marcavam as comunidades rurais agora dá lugar a uma heterogeneidade crescente e a um processo de individualização e racionalização da vida social, mudando formas de solidariedade e de cooperação locais, agora mais mediadas pela definição de formas de ação coletiva que vão além do pertencimento ao grupo familiar ou à tradição local e introduzindo crescente monetarização da vida social, antes apoiada em trocas mais diretas e muitas vezes não monetárias. $\mathrm{O}$ relacionamento com as cidades, o último elemento distintivo da ruralidade, agora não se baseia mais exclusivamente na exportação de produtos primários aos centros urbanos. Em vez disso, surge complexa trama espacial de atividades envolvendo diferentes setores da economia local, com consequências particulares para a estrutura de composição das rendas e para a ocupação da força de trabalho. Em alguns lugares, há também uma mudança nos fluxos demográficos. O êxodo rural não é mais tendência generalizada em todo o mundo. Em seu lugar, surgem fenômenos relativamente novos como migração de retorno ou gentrificação rural. Isso cria novas situações, novos conflitos e novas possibilidades de inserção ou exclusão, que devem ser entendidas em termos de cada configuração territorial específica e da diversidade de composições das relações entre o urbano e o rural.

Essas mudanças obviamente se materializam em graus muito diferentes em cada contexto regional. No entanto, em geral, seu sentido dificulta que se continue a tratar o "mundo rural" exclusivamente como oposto do "mundo urbano", de proclamar seu desaparecimento ou resumi- 
lo a apenas uma de suas dimensões atuais: a dimensão agrícola e agrária. Por isso, o enfoque territorial e relacional faz mais sentido para as dinâmicas contemporâneas do que o enfoque setorial e dicotômico que predominou no decorrer do século XX. Consequentemente, a mensagem-chave a esse respeito é evitar as dicotomias mencionadas anteriormente ao se abordar a especificidade dos modos de vida rurais e seu potencial para, por um lado, reduzir a pobreza, e por outro melhorar a contribuição destes agricultores e das áreas rurais para seus países. Para fazer isso, é necessário operar com um conjunto de instâncias empíricas relevantes, nos seguintes termos:

- Mix de rendas agrícolas e rendas obtidas fora da atividade agropecuária - A finalidade de ações públicas deve ser preservar e reforçar a autonomia mínima das famílias rurais na condução de suas estratégias de reprodução social. Este é um grupo social que se organiza basicamente em torno do uso intensivo do trabalho, e menos intensivo em capital. Com base na ideia de modos de vida rurais, é preciso sempre facilitar ou incentivar um conjunto amplo de estratégias adotadas diferenciadamente por parte dos diferentes grupos sociais. Isso significa que, em relação às fontes de renda, em particular, aquelas derivadas de atividades agrícolas são tão importantes quanto aquelas obtidas em outras atividades e formas de emprego de sua força de trabalho (as ocupações não agrícolas e a pluriatividade permanente ou temporária). O mesmo vale para rendas obtidas com migração permanente, temporária ou, ainda, para o acesso a formas de proteção social que implicam ingressos monetários como transferências condicionais de renda.

- Mix de rendimentos monetários e não monetários - No caso das populações rurais, e especialmente dos mais pobres, baixos níveis de renda podem não ser um indicador suficiente de privação. $O$ sentimento de privação e os meios para reduzir a vulnerabilidade estarão sempre relacionados aos modos de vida experimentados por essas populações, que muitas vezes consideram aspectos não monetários como extremamente importantes para seu bem-estar. Este é o caso notável de produção de alimentos para autoconsumo e seu impacto na segurança alimentar e nutricional, ou do acesso a terra como local de residência, um conjunto de fatores que podem reduzir o custo monetário da reprodução social para as famílias.

- Interdependência entre sistemas ecológicos e sociais - De forma mais explícita e direta do que do que para habitantes urbanos, para populações rurais a interdependência entre sistemas sociais locais e os sistemas ecológicos que os sustentam é decisiva e imediata. A qualidade e a forma de uso dos recursos naturais são simplesmente fundamentais por vários motivos. Primeiro, para entender a vulnerabilidade dessas populações, uma vez que o esgotamento 
de um determinado recurso (solo, água, florestas, sementes) pode simplesmente eliminar a base material de suas formas de subsistência e de suas interações sociais. Em segundo lugar, as melhores formas de usar esses mesmos recursos constituem um potencial para superar condições de privação e buscar aumentos na produtividade. Daí a importância de se considerar, no enfrentamento da pobreza, uma avaliação do estado dos recursos naturais e seu fluxo, a elaboração de projeções sobre a situação futura desse estoque, prever riscos e antecipar soluções para reduzir a vulnerabilidade, formular alternativas para seu melhor aproveitamento e sua produtividade. Isso se torna ainda mais sensível em um contexto de mudanças climáticas, cujos efeitos sobre os serviços ecossistêmicos tende a ser brutal.

- Interdependências entre áreas rurais e centros urbanos próximos As políticas de combate à pobreza rural tradicionalmente isolam, em seu desenho, áreas rurais e seus moradores em relação às áreas urbanas. No entanto, precisamente devido à densidade populacional relativamente baixa e, consequentemente, também devido à distância dos principais centros urbanos, as áreas rurais devem ser entendidas em complementaridade com as cidades de que dependem para atender a parte de suas necessidades, como acesso a mercados ou infraestrutura social. No caso dos espaços rurais situados perto dos centros urbanos essa interdependência é ainda mais forte, porque famílias rurais tendem a fundir oportunidades para obter renda nos mercados de trabalho rural e urbano, conforme mencionado.

Muito embora os aspectos até aqui mencionados já sejam razoavelmente conhecidos na literatura sobre pobreza e desenvolvimento rural, no âmbito governamental é forçoso reconhecer que as inovações produzidas têm se apoiado fortemente na visão unidimensional, preocupando-se com a garantia de acesso a rendas mínimas, ou tenham chegado ao máximo até o segundo momento da periodização apresentada aquele em que se passa da visão unidimensional da pobreza como privação de renda à ideia de pobreza como algo multidimensional. Pouco se vê na direção de um enfoque relacional que estabeleça um diálogo substantivo com a pluralidade dos modos de vida ou que opere satisfatoriamente com o conjunto de complementaridades e interdependências assinaladas. A adoção do enfoque territorial nas políticas para o mundo rural, na virada do século, embora altamente promissor, revelou-se algo limitado nos resultados efetivamente produzidos (FAVARETO; BERDEGUÉ, 2018). A próxima seção está voltada justamente a um rápido exame da trajetória recente das políticas de combate à pobreza na região. 


\section{A trajetória das políticas de combate à pobreza rural e seus ensinamentos}

Resumidamente, a trajetória das políticas de desenvolvimento rural e redução da pobreza nos países latino-americanos também pode ser apresentada sob a forma de uma periodização organizada em três momentos básicos: o período da modernização agrícola, sucedido pela etapa em que se buscou ampliar instrumentos e dimensões sob a ideia de um enfoque integral, e finalmente o período mais recente, marcado pelos programas de transferências condicionadas de ingressos e por tentativas de introduzir o enfoque territorial.

\section{Modernização agrícola}

O primeiro passo, experimentado principalmente entre os anos 1950 e 1980, enfatizava a melhoria dos sistemas de produção como forma de superação dos limites de ingressos monetários entre famílias rurais. Os instrumentos de política pública de modernização agrícola, como o acesso ao crédito e o uso intensivo de tecnologia, levaram a fantásticos níveis de aumentos de produtividade que alcançaram agricultores de grande porte e, em muitos lugares, uma camada mais restrita embora importante dos agricultores de pequeno porte. Mas houve, também, o conhecido e acentuado processo de seletividade competitiva. A expectativa era que tal processo de diferenciação social formaria uma classe de grandes e pequenos agricultores inseridos em mercados. As pessoas que não atingissem este nível de produtividade e competitividade seriam absorvidas como empregados no mercado de trabalho agrícola ou migrariam para as cidades para participarem nos mercados de trabalho urbanos, então em expansão. A história, no entanto, mostra que isso não ocorreu. E, em vez de promover uma absorção pelo mercado de trabalho, a modernização agrícola teve como contrapartida um acentuado processo de exclusão social e uma crescente desigualdade, sem falar na explosão urbana e na constituição de uma classe trabalhadora com poucos direitos e um patamar de remuneração rebaixado (GARCIA, 2003).

\section{Desenvolvimento rural integral}

Dirigindo-se precisamente aos agricultores que não se beneficiaram das políticas de modernização, a segunda etapa das políticas de desenvolvimento rural e redução da pobreza deu forma às chamadas "políticas e programas integrados de desenvolvimento rural". O objetivo dessas iniciativas, implementadas principalmente nas décadas de 1980 e 1990, era melhorar condições de produção e, ao mesmo tempo, 
proporcionar condições de vida satisfatórias para famílias de agricultores. Algo aparentemente coerente com uma abordagem mais abrangente dos problemas, como reivindicado na seção anterior. Dois problemas levaram ao fracasso dessas iniciativas: a) dificuldades na mobilização de recursos em volume suficiente para enfrentar situações históricas de privação em muitas dimensões da vida das pessoas; afinal estas décadas foram marcadas por forte crise na capacidade de financiamento dos Estados latino-americanos; b) fortes limites na coordenação entre diferentes níveis e áreas de governo. O resultado foi um efeito bastante limitado dessas iniciativas, apesar do alto custo de sua implementação. Experiências bem-sucedidas resumiramse a casos isolados (GARCIA, 2003). E, embora a literatura da época não tenha mencionado, hoje se conhece um terceiro fator importante que explica o fracasso: os problemas foram identificados como internos aos limites dos estabelecimentos agropecuários, quando algumas das limitações diziam respeito ao ambiente social e institucional, caso do frágil acesso a mercados, o que realça uma vez mais a necessidade de se superar aquele conjunto de dicotomias e simplificações já mencionadas e de se caminhar em direção a um enfoque relacional, multidimensional, algo em torno do qual a abordagem territorial tentaria se apoiar anos mais tarde.

\section{As transferências condicionadas de ingressos e os programas de desenvolvimento territorial}

A terceira geração de políticas optou por maior pragmatismo na luta contra a pobreza rural. O êxito de iniciativas de transferências condicionadas de renda expandiu a adoção de tais instrumentos em diferentes países, com impacto notável nas condições de vida de pobres rurais (IFAD, 2016). É verdade que nem toda a redução da pobreza experimentada nos últimos 15 ou 20 anos se deve exclusivamente a este tipo de programas. Contaram positivamente, também, a trajetória de crescimento econômico que continua sendo vivenciada por muitos países da região, em parte impulsionada pelo ciclo de expansão da demanda internacional por commodities, o que impactou as exportações e as receitas dos países, com reflexos na vitalidade do seu mercado de trabalho interno e nos investimentos em infraestrutura e na expansão de serviços vitais à garantia de direitos sociais nas áreas de educação e saúde. Esses investimentos e a maior disponibilidade de recursos levaram a um crescimento do emprego formal. E, em alguns casos, políticas de valorização salarial ampliaram oportunidades de inclusão via setor produtivo. Complementarmente, muitos países lançaram programas de segurança alimentar ou iniciativas de compras públicas da agricultura familiar. Em 2016, segundo Maldonado et al. (2016), os programas de transferência condicionada de renda na América Latina e Caribe atendiam cerca de 27 milhões de famílias, representando cerca de 
113 milhões de pessoas, o equivalente a um quinto da população e quase metade da população em condição de pobreza da região. No entanto, o grau de desarticulação dessas iniciativas ainda é alto e seus resultados pouco consolidados. Diante do risco que representa a dependência das transferências, algo particularmente grave em tempos de crise econômica, muitos países identificaram a necessidade de buscar melhor integração entre as políticas de proteção social com políticas produtivas (MALDONADO et al., 2016).

O caso brasileiro é exemplo típico desse movimento. Durante os anos da intensa modernização agrícola, marcadamente entre os anos 1970 e 1980, os índices de desigualdade cresceram e os indicadores de pobreza se mantiveram altos. Nos anos 1990, quando houve relativa estabilidade, aproximadamente um em cada três brasileiros era considerado pobre, a maior parte deles vivendo em áreas rurais. Nos anos 2000 o combate à pobreza e à fome tornou-se uma prioridade do Estado. Inicialmente, por meio do Programa Fome Zero se buscava mobilizar uma arquitetura institucional bastante complexa. Embora esse programa tenha sido mantido ao longo dos 15 anos seguintes, gradativamente o foco da política de combate à pobreza se deslocou para o Programa Bolsa Família (PBF), que garantia a transferência de ingressos às famílias em condição de pobreza mediante contrapartidas relacionadas à educação e à saúde básica das crianças do grupo familiar atendido. Esse programa levou a um alívio imediato da fome e da pobreza entre famílias carentes. Um dos principais aspectos do desenho institucional do PBF com impacto decisivo nos resultados alcançados foi a criação do Cadastro Único, uma base de informações sobre as famílias pobres que unificava as várias existentes, até então dispersas em diferentes estruturas ministeriais, facilitando, assim, o trabalho de focalização e da chamada "busca ativa", para fazer com que os instrumentos de políticas públicas pudessem chegar até a população em condição de privação. Simultaneamente o país experimentava também uma trajetória continuada de crescimento econômico e aquecimento do mercado de trabalho, uma diretriz de valorização do salário mínimo acima da inflação, e alto grau de experimentação nas políticas públicas, com criação de vários programas voltados à agricultura familiar (GRISA; SCHNEIDER, 2015).

Com bons indicadores alcançados entre famílias pobres, novo passo foi dado com a criação do Programa Brasil Sem Miséria, a partir de 2011, agora voltado para famílias em condição de pobreza extrema. Junto do Cadastro Único uma ágil estrutura institucional foi montada para fazer com que diferentes políticas e programas chegassem a essas famílias: o programa foi colocado a cargo do Ministério do Desenvolvimento Social e uma sala de situação, com membros de diferentes ministérios e com acesso direto à Presidência da República, foi criada para garantir agilidade na tomada 
de decisões e no desbloqueio de impedimentos à boa execução das ações. Recursos adicionais foram alocados nos ministérios que passaram a compor o programa. Assim, a prioridade dada ao programa se traduziu em uma estrutura de gerenciamento e tomada de decisões com mandato, recursos e agilidade para colocá-la em prática, mostrando que, quando há prioridade, a coordenação tão desejada acontece (LOTTA; FAVARETO, 2016). Três iniciativas compunham o programa: garantia de renda, para alívio imediato da situação de extrema pobreza; inclusão produtiva, com o objetivo de aumentar capacidades e oportunidades de trabalho e geração de renda; e acesso aos serviços públicos, visando a melhorar condições de educação, saúde e cidadania das famílias. No seu conjunto, o programa mobilizava 12 diferentes ministérios e uma complementaridade com os serviços de assistência social nos municípios do país, responsáveis pela "busca ativa" e pela coordenação das iniciativas no plano local (CAMPELLO et al., 2014).

Qual é o balanço que se pode fazer dessa iniciativa que alcançou ampla repercussão internacional? $O$ primeiro e mais evidente foi a efetiva e expressiva redução da pobreza. Ainda que se deva uma vez mais mencionar que algo neste êxito se deve também à recuperação do emprego e à valorização salarial do período, é inegável que as transferências condicionadas foram fundamentais para fazer com que, no meio desta década, o país tivesse reduzido o percentual de pobres de 23,3\% em 2001 para $7 \%$ em 2014. Entre a população rural, a redução foi de $48,9 \%$ para $20,2 \%$. No que diz respeito à extrema pobreza, a redução foi de $8,3 \%$ para $2,5 \%$ no mesmo período. Entre a população rural, a extrema pobreza caiu de 21,8\% para 7,6\% no mesmo período. Os dados resultam de tabulação especial do Instituto Brasileiro de Geografia e Estatística (IBGE) feita para o Ministério do Desenvolvimento Social (MDS) (BRASIL, 2015).

Um segundo aspecto é a contribuição desse tipo de investimento ou gasto social para a dinamização de economias locais em regiões rurais. Estimativas apontam que, para cada real transferido a estas populações pobres, se gerava $\mathrm{R} \$ 1,60$ (um real e sessenta centavos) de movimento na economia local, a partir dos efeitos de encadeamento impulsionados com gastos das famílias. Repercutindo ideias já formuladas décadas atrás por Amartya Sen, a política social de combate à pobreza se convertia em dinamizador do crescimento econômico nestas regiões de débil atividade produtiva.

Um terceiro aspecto, não menos importante, é justamente a arquitetura institucional do programa. O Cadastro Único permitiu maior focalização e coordenação em torno do público-alvo. O grau de prioridade conferido à iniciativa subordinou interesses particulares de áreas de governo a um objetivo estratégico compartilhado. A divisão de tarefas entre governo central e governos municipais permitiu mobilizar recursos que somente o 
poder central poderia articular, e uma capilaridade que apenas governos municipais poderiam operar.

Um quarto aspecto diz respeito à narrativa sobre a pobreza, agora tratada como tema multidimensional e não exclusivamente como problema de acesso a determinado nível de ingressos monetários. O alívio da pobreza mediante transferências de renda era complementado com acesso a serviços sociais que permitiriam enfrentar a privação de capacidades fundamentais, também na direção preconizada pela abordagem das capacitações. E, finalmente, a estratégia de inclusão produtiva buscava fazer com que a dependência das transferências condicionadas fosse entendida como uma posição de vulnerabilidade transitória e que poderia ser superada via inclusão nos mercados de trabalho ou via melhoria dos sistemas produtivos entre agricultores familiares pobres.

Como em qualquer iniciativa bem-sucedida, entretanto, há sempre desafios que restaram a superar e na experiência brasileira não foi diferente. Um quinto aspecto que se deve mencionar diz respeito justamente à dificuldade experimentada com a estratégia de inclusão produtiva. Ela estava baseada em uma rota, segundo a qual após o alívio da pobreza mediante acesso às transferências de ingressos, condições básicas de vida e de produção seriam garantidas ao grupo familiar foco do programa: acesso à água, energia elétrica e assistência técnica estavam entre estas condições a serem viabilizadas por programas específicos. E, em um segundo momento, um crédito de fomento deveria auxiliar esses agricultores a melhor estruturarem sua produção para alcançar a venda de excedentes. Finalmente, o acesso a programas de compras públicas serviria como estímulo para estabilizar essa oferta, que poderia ser, posteriormente, ampliada para vendas diretas em circuitos curtos ou outras oportunidades de mercado. Levantamentos realizados mostram, entretanto, que a oferta de serviços para viabilizar essa sequência de investimentos como planejado raramente aconteceu (MELO, 2017). Houve problemas de sincronização: em alguns casos o crédito de fomento chegou fora do tempo necessário para viabilizar o plantio ou de forma desconectada da assistência técnica; nem sempre os agricultores incluídos em programas de compras públicas como o Programa de Aquisição de Alimentos ou o Programa Nacional de Alimentação Escolar foram aqueles que receberam o crédito e a assistência técnica. Isso porque, apesar da tentativa de coordenação, cada ministério responsável continuava com seu calendário de execução e com prioridades regionais que dificultaram a articulação intersetorial. Os problemas de coordenação apareciam também no que diz respeito à articulação intergovernamental, porque o desenho e a coordenação do programa foram bastante centralizados, apesar da execução decentralizada. E nesta descentralização, pouco houve de diálogo ou diferenciação em realidades 
locais específicas. O mesmo pacote era ofertado a todas as localidades, que apontavam prioridades locais dentro daquele leque de opções de políticas. Além disso, a inserção produtiva requer certas capacidades com as quais governos locais raramente contam, dificultando a coordenação federativa ou intergovernamental. Para completar, oportunidades de mercado com programas de compras públicas são limitadas por definição, o que requereria formas de coordenação entre Estado e mercado que, no entanto, foram praticamente inexistentes. Tudo isso acabou por limitar as possibilidades de inclusão produtiva das famílias rurais, embora sua condição de privação tenha sido bastante melhorada com os investimentos feitos, como já mencionado.

Um sexto aspecto diz respeito à narrativa sobre a pobreza. Parte da sociedade brasileira, embora reconhecendo os méritos do programa, passou a tomar como critério de sucesso a viabilização de oportunidades permanentes de renda que diminuíssem gradativamente a necessidade de transferências de renda: a chamada "porta de saída" do programa. Essa retórica deixa de lado um aspecto fundamental: diante das características do atual momento do capitalismo internacional, a pobreza e a exclusão tornaram-se estruturais. Não se está mais no período de pleno emprego dos 30 anos gloriosos do pós-guerra do século XX, como bem o demonstra a obra de Thomas Piketty (2015) e sua ênfase na desigualdade crescente como fenômeno intrínseco da economia internacional atual. E em tal quadro, a "porta de saída" é uma porta giratória: aqueles que alcançam alguma oportunidade de emprego ou de mercado hoje tendem a perdêla amanhã e, com isso, voltam a depender de transferências de ingressos. Embora não se deva condenar e naturalizar a dependência desse tipo de instrumento, é preciso reconhecer que tais políticas e programas serão, doravante, permanentes, sob pena de ver o número pobres aumentar ano após ano. Este fator pode ser minimizado, desde que se encontre um novo estilo de desenvolvimento, diferente das duas narrativas que foram experimentadas até aqui pelos países latino-americanos. Isto é, não será via industrialização por substituição de importações, nem por via das exportações de commodities que a inclusão produtiva dos mais pobres será alcançada, posto que estas são vias de crescimento econômico altamente poupadoras de trabalho. Será preciso reinventar a economia dos países e das regiões rurais, tendo como vetores novas formas de uso dos recursos naturais, uma diversificação econômica para além da agricultura, a valorização e melhoria da produtividade da produção de pequena escala hoje em condições artesanais ou próximo disso, e atividades econômicas que possam ser motivadas justamente pelos investimentos sociais. Isso, no entanto, ainda não conformou uma narrativa com portadores e com peso social suficiente para influenciar o debate público em outra direção. 
Essas dificuldades enfrentadas pela bem-sucedida experiência brasileira também se fizeram presentes em ao menos outras duas ações muito relevantes no contexto latino-americano, levadas adiante pelos governos do Peru e do México. No caso peruano, o Programa Nacional de Apoyo Directo a los Más Pobres - conhecido como Juntos - surgiu em 2005. Graças ao período de sua criação, foi possível apoiar-se na experiência de outros programas de transferências, dentre eles o Bolsa Família. A criação de Juntos, assim como no caso do Brasil sem Miséria e do mexicano Prospera, envolveu a reunião de diversos programas sociais que já vinham sendo implementados nos respectivos países, dando-lhes melhor articulação e maior escala. O programa previa a entrega de uma transferência direta às famílias beneficiadas. Como contrapartida, beneficiários firmavam um "convênio de participação", prevendo frequência escolar mínima para crianças e participação em determinados programas sociais.

Assim como na experiência dos outros países citados, juntamente com a transferência de renda havia o intuito em romper com a pobreza por meio do desenvolvimento de capacidades. Nos documentos oficiais se menciona, entre elas, inserção produtiva com ênfase em projetos de segurança alimentar e em projetos que aumentem a produtividade. Para isso, foram criados ou mobilizados programas que incidiam sobre este tema.

O primeiro esforço envolveu a mobilização do Ministério de Agricultura peruano para que levasse intervenções produtivas aos lugares que recebiam benefícios do programa Juntos, o que não alcançou completo êxito. Como alternativa, foi criado um programa de inclusão produtiva dentro do próprio Ministério do Desenvolvimento Social. O programa criado, Haku Wiñay, tinha por objetivo fomentar o desenvolvimento de capacidades e o aumento da produtividade dos beneficiários do programa Juntos e foi implementado em localidades com alta incidência destes beneficiários. Além do Haku Wiñay, outras ações de inclusão produtiva vinham sendo implementadas nos marcos do plano de diversificação produtiva e pela Estrategia de Desarrollo e Inclusión Social (ENDIS), porém, com baixo grau de coordenação com as ações do Juntos, o que fez com que a mais destacada iniciativa no que tange à inclusão produtiva das populações mais pobres continuasse sendo o Haku Wiñay. Magnani (2016) sumariza os quatro principais componentes do programa: o primeiro componente incentiva o fortalecimento e consolidação dos sistemas de produção dos agricultores familiares, com oferta de um pacote de assistência técnica que, por sua vez, coloca ênfase no melhoramento dos sistemas de produção familiar com a adoção de inovações tecnológicas de baixo custo, flexíveis e adequadas ao meio. Para alcançar o objetivo proposto, ainda são entregues insumos para produção, como animais de pequeno porte, materiais e equipamentos de sistema de água, cultivos de hortaliças, adubos. $\mathrm{O}$ segundo 
componente engloba ações para auxiliar na melhoria da situação domiciliar dos beneficiários. Neste quesito, são desenvolvidas atividades de assistência técnica para melhoramento da condição da habitação e para auxiliar na adoção de práticas saudáveis de armazenamento, preparação e consumo de alimentos. São providas, também, a construção de cozinhas melhoradas e módulos de captação de água e manejo de resíduos sólidos. O terceiro componente do programa tem a intenção de auxiliar a promoção de negócios rurais inclusivos. Neste quesito, são feitas chamadas nas quais agricultores familiares beneficiados devem competir por financiamento de seus planos de negócios, que, por sua vez, devem ser orientados ao desenvolvimento do mercado local. Os Comités Locales de Asignación de Recursos (CLAR) ficam responsáveis por avaliar propostas apresentas e elegem os ganhadores, que receberão recursos para financiamento de assistência técnica específica e para a compra de insumos e equipamentos de baixa escala. $\mathrm{O}$ quarto e último componente fomenta capacidades financeiras, mediante promoção de informação e conhecimentos básicos acerca do sistema financeiro. Neste componente, são desenvolvidas atividades de capacitação à população beneficiada ajudando-a no uso consciente de instrumentos financeiros como contas bancárias, contas poupança, entre outros.

Escobal e Ponce (2016) em avaliação das tentativas de articular proteção social e inclusão produtiva na iniciativa peruana destacam alguns aspectos. Primeiramente, a melhoria das condições de infraestrutura das casas levou a um considerável aumento no nível da condição de vida das famílias. Vários indicadores de bem-estar associados a esta melhoria incidem sobre privações fundamentais sobretudo na saúde, atestando que houve grau satisfatório de atendimento a dimensões da pobreza que vão além da renda. Em segundo lugar, apesar da dificuldade do programa em lidar com a heterogeneidade da pobreza e dos territórios onde é implementado, buscou-se um desenho flexível no qual um "menu" de serviços podia ser escolhido pela comunidade atendida. Sobre este tema, ainda, houve adaptação do Haku Wiñay para a realidade da Amazônia, por meio da iniciativa Noa Jayatai. Porém, como mostram os autores, o programa não deveria atender apenas as diversidades do território mas também as diversidades de interesse dos beneficiários:

[...] se debe reconocer que, em intervenciones como Haku Wiñay, se tiene que trabajar com poblaciones sumamente heterogéneas, a pesar de que compartan altos niveles de vulnerabilidade y uma baja dotación de activos. Es necessário aceptar, por ejemplo, que el objetivo para algunos hogares es reducir su vulnerabilidad y alcanzar mayores niveles de seguridad alimentaria. Dadas las capacidades existentes y la base exígua de actiovs de este grupo, exigir que ellos alcancen metas de mejora em los ingresos monetários, generados a partir de la venta en el mercado, podría ser poco realista e, incluso, contraproducente. (ESCOBAL; PONCE, 2016, p. 189). 
O terceiro aspecto a considerar, em termos de ingressos, conforme apontam os autores, é que atividades vinculadas ao primeiro componente do programa - fortalecimento e consolidação do sistema de produção familiar - permitiram um incremento da produção agrícola e pecuária tanto para autoconsumo como para venda. O estudo indica ainda que $80 \%$ dos ingressos das famílias tratadas na amostra conseguiam ingresso no mercado de trabalho. Entre 2013 e 2015, ou seja, durante a implementação do Haku Winãy, realizou-se uma mudança no padrão de ingresso das famílias estudadas: houve incremento de 7\% nos ingressos ao mercado de trabalho autônomo em geral e aumento de renda a partir de atividades independentes vinculadas a serviços, comércio, atividades artesanais. Ademais, apontam que os próprios beneficiados verificaram melhoria de ingresso: $67 \%$ das famílias tratadas na amostra do estudo reconhecem que seus ingressos têm melhorado durante os últimos anos e $68 \%$ consideram que os ingressos no mercado de trabalho em seu povoado têm melhorado consideravelmente. $\mathrm{O}$ quarto aspecto parece ser o ponto mais sensível da atuação do Haku Wiñay. Como aponta Magnani (2016), o projeto em questão foi desenhado para ser implementado em zonas onde a cobertura do programa Juntos é importante, buscando aproveitar sinergias de ambos para reduzir a vulnerabilidade das famílias mais pobres. A autora aponta que, ao final de 2012, a presença de Juntos e Haku Wiñay em uma mesma área de atuação era substantiva: 60,8\% das famílias eram beneficiarias dos dois programas. Porém, citando a ex-ministra da área social, Carolina Trivelli, aponta que a coordenação de ambos deixou a desejar, revelando êxito parcial: em suas palavras, "[...] más que programas articulados fueron programas que concurrieron en el mismo lugar” (MAGNANI, 2016, p. 27).

No caso mexicano, o programa de transferência de renda surgiu em 1997, com o nome PROGRESA (Programa de Educação, Saúde e Alimentação), cujas ações inicialmente abrangiam apenas 300 mil famílias (MAGNANI, 2016). Em 2002 o programa foi ampliado, mudou de abrangência e foi renominado como Oportunidades. Em 2014, houve nova ampliação e passou a ser chamado PROSPERA - Programa de Inclusão Social, articulando e coordenando diversas políticas sociais, incluindo inclusão produtiva. Assim como nos programas já mencionados dos casos brasileiro e peruano, a família beneficiada tem de cumprir contrapartidas na área da saúde e educação. Os benefícios e apoios do programa abrangem diversas áreas, coerente com um enfoque multidimensional, como educação, assistência, alimentação e saúde. Como relata Magnani (2016), uma das maiores novidades do PROSPERA foi a tentativa de articular iniciativas voltadas à inclusão no mercado de trabalho, inclusão financeira e inclusão produtiva. A inclusão produtiva mexicana, assim como a brasileira, tem como propósito incrementar a transferência de renda mobilizada pelas políticas 
sociais com o desenvolvimento econômico e produtivo das famílias. Da mesma forma, portanto, a estratégia mexicana busca coordenar programas por meio do acesso prioritário a mais de uma dezena de iniciativas: Programa de Apoyo para la Productividad de la Mujer Emprendedora; Programa de Apoyo a Jóvenes para la Productividad de Futuras Empresas Rurales; Programa de Productividade Y Competitividad Agroalimentaria; Programa Opciones Productivas; Programa del Fondo Nacional para el Fomento de las Artesanías; Fondo para el Apoyo a Proyectos Productivos en Núcleos Agrarios; Programa de Fomento a la Agricultura; Componente Acceso al Financiamiento Productivo y Competitivo; Programa Integral de Desarrollo Rural; Programa para el Mejoramiento de la Producción y Productividad Indígena; Programa de Fomento a la Economía Social; Bécate; Fomento al Autoempleo, el Fondo Nacional del Emprendedor y Programa para la Constitución y Operación de Unidades e Promoción de Crédito de Garantías Líquidas y Reducción de Costos de Acceso al Crédito. Estes programas são geridos por distintos ministérios: a Secretaria de Agricultura, Ganadería, Desarrollo Rural, Pesca y Alimentación (Sagarpa), que gerencia seis programas; a Secretaria de Desarrollo Agrário, Territorial y Urbano (Sedatu), com dois programas; a Sedesol (Secretaria de Desarrollo Social Sedesol), também com dois programas, além da Secretaria de Trabajo y Previsión Social (STPS) e da Secretaria de Economía (SE).

Para Naude et al. (2017), a questão da coordenação dos programas mexicanos não foi satisfatoriamente resolvida: é preciso coordenação de programas dentro e entre distintas áreas do governo federal, regional e municipal para evitar duplicidade de apoios, estabelecer regras de operação que definam precisamente público potencial, público-alvo e abrir a efetiva possibilidade de que o acesso a distintos programas se dê de forma complementar aos beneficiários. Foi pensando nisso que se lançou, em 2014, a ideia de um programa específico nos marcos do PROSPERA, o Programa Territorios Productivos (BERDEGUÉ et al., 2015). O desenho desta iniciativa previa, em primeiro lugar, uma organização e articulação das iniciativas a partir de um território definido com base em critérios funcionais, a partir da unidade formada por uma trama de deslocamentos da população local em um espaço determinado formado por diferentes municipalidades e com certa regularidade. Três componentes conformavam a iniciativa: organização e mobilização da população local; fortalecimento de sua base produtiva; e articulação de demais programas e iniciativas. Trata-se de experiência ainda recente, mas com o mérito de buscar conectar formas de inserção social e de inserção produtiva, articulando-as sob um explícito enfoque territorial.

Essa breve recuperação da trajetória recente das políticas de combate à pobreza permite inferir um conjunto de aspectos que deveriam ser 
considerados em iniciativas futuras, listados esquematicamente a seguir. Juntos, estes aspectos, listados a seguir, formam uma espécie de consenso básico sobre lições aprendidas nas últimas duas décadas ou mais:

- Enfoques unidimensional, multidimensional e relacional - $\mathrm{O}$ contraste entre a evolução das abordagens teóricas e das abordagens praticadas pelas políticas públicas evidencia que ainda há espaço para transformar os achados das pesquisas e do conhecimento acumulado sobre como enfrentar a pobreza em inovações de políticas públicas. Apesar da ênfase nas transferências condicionadas de renda, muitas iniciativas já transitam por um enfoque multidimensional, agregando outras dimensões aos programas de combate à pobreza. Em especial, três aspectos poderiam ajudar na transição em direção ao que se está chamando aqui de enfoque relacional: a) maior diálogo com os modos de vida das populações rurais no próprio desenho das políticas públicas, para além da ideia de deixar às populações locais que "escolham" entre um menu de políticas; b) maior ênfase nas articulações entre pobreza e desigualdades, posto que a condição de pobreza não é absoluta e sim relativa às distâncias perante outros grupos sociais no acesso a oportunidades; c) busca pela superação de um conjunto de dicotomias, em especial aquelas que marcam a dimensão econômica e a dimensão social, aquela relativa à separação entre estas duas dimensões e a dimensão ambiental, e ainda a que envolve o universo rural e o urbano.

- Diferentes rotas de saída da pobreza - A ideia de rotas de saída da pobreza já é um avanço em relação à simples oferta de pacotes de apoio à população-alvo de políticas e programas. Ela indica a necessidade de certa cumulatividade e sequenciamento nos apoios providos por políticas públicas. Porém, ainda há pouca inovação em torno do desenho de diferentes rotas, de forma a permitir maior aderência à diversidade dos modos de vida das populações rurais ou à diversidade de contextos territoriais em que estão inseridas. De forma esquemática, pode-se afirmar que há ao menos cinco distintas rotas que podem ser operadas por programas e políticas públicas: a) A rota estabelecida desde políticas setoriais tradicionais: envolve a entrada junto aos beneficiários utilizando a porta das políticas agrícolas e agrárias. Faz sentido justamente entre os que já são beneficiários deste tipo de instrumento. E, a partir deles, podem ser mobilizados outros programas e outras áreas. b) A rota estabelecida desde políticas sociais: envolve a entrada junto aos beneficiários dos programas de transferências condicionadas de ingressos. A partir deste apoio destinado ao alívio da pobreza, pode-se desenhar um caminho de consolidação e uma melhor estruturação das estratégias de vida destes grupos familiares. c) A rota estabelecida desde políticas 
territoriais: envolve a entrada junto à população local desde um projeto desenhado com características territoriais, para uma região, uma bacia hidrográfica ou de emprego, a área de influência de um grande projeto, atividade econômica ou obra de infraestrutura. d) A rota estabelecida desde políticas de conservação ambiental: em alguns territórios os projetos estratégicos de superação da pobreza terão de ser associados a formas efetivas de conservação ambiental; ainda que esta deva ser uma dimensão presente em todas as demais rotas, em certos casos a conservação, em si, de uma determinada base de recursos é que deverá ser base de todas as demais iniciativas; e) A rota estabelecida desde projetos especiais de interesse do conjunto da sociedade de um país: esta rota envolve a articulação de vários instrumentos e recursos em torno de uma iniciativa que mobilize uma espécie de ideia força; por exemplo, a ideia de sistemas agroalimentares saudáveis pode ser uma motivadora e catalizadora de atores, energias e recursos capazes de mobilizar a saída duradoura da pobreza de amplos contingentes populacionais. $\mathrm{O}$ importante é que estas rotas não sejam vistas como caminhos totalmente separados. E, em cada um deles, um conjunto de critérios deverá estar presente. São apenas caminhos diferentes para pôr em movimento uma mesma concepção e um mesmo enfoque relacional, como dito anteriormente. É claro que instrumentos presentes em uma rota podem ser mobilizados em outra. Trata-se, isso sim, de pensar diferentes composições a partir de motivadores distintos e mais aderentes aos modos de vida e aos conflitos e bloqueios vividos por grupos sociais específicos, em vez de uma única e linear rota de superação da pobreza.

- Temas sensíveis 1: Segurança alimentar e agricultura sustentável Pode-se elencar uma grande variedade de temas sensíveis, isto é que requerem a atenção ao mobilizar capacidades e formar uma nova narrativa sobre a superação da pobreza rural na América Latina. Um deles, sem dúvida, envolve segurança alimentar e agricultura sustentável. De um lado, há a fome e a desnutrição; de outro, a obesidade. São extremos que se tocam e resultam da inabilidade das sociedades latino-americanas em mobilizar sua significativa disponibilidade de recursos naturais para satisfazer de forma saudável as necessidades alimentares de seus cidadãos. Uma transição em direção a modelos mais saudáveis e sustentáveis de alimentação não será resultado de políticas de nicho. Será preciso redesenhar um conjunto de aspectos culturais, institucionais e tecnológicos. Mas não há dúvida de que aqui reside grande oportunidade de mobilizar recursos, com a vantagem adicional de que esta pode ser uma das bases das rotas mencionadas. 
- Temas sensíveis 2: Integração entre proteção social, proteção ambiental e inclusão produtiva - Até aqui governos de diferentes países vêm buscando, ainda sem sucesso eloquente, formas de aproximar instrumentos de proteção social de instrumentos de inclusão produtiva. Seria preciso adicionar aqui um terceiro desafio: articular aos dois anteriores os instrumentos de proteção ambiental. A literatura mostra que a dimensão ambiental é inseparável das duas anteriores. Mais ainda quando se considera o tipo de transição tecnológica que as sociedades latino-americanas terão de fazer no decorrer deste século XXI para fazer frente às mudanças climáticas. Outro aspecto ainda diz respeito à potencialidade econômica dessas formas inovadoras de promover a conservação ambiental. Tudo isso é razão mais do que suficiente para que se busque esta tripla articulação. Ela significa uma necessidade prática, uma oportunidade diante do novo contexto, e seria totalmente coerente com a retórica dos ODS e da Agenda 2030 em uma perspectiva de pôr em prática a interdependência entre os diferentes objetivos ali mencionados.

- Temas sensíveis 3: desigualdades territoriais em infraestrutura básica - A integração social e produtiva das famílias rurais pobres depende não apenas dos atributos internos do grupo familiar e de suas capacidades. Depende também de condições externas como acesso ao financiamento e equipamentos sociais. Não há projeto produtivo ou transferências de ingressos que possam lograr a superação duradoura da pobreza em um ambiente social no qual a oferta destes equipamentos sociais guarda enorme distância em relação aos níveis encontrados em regiões urbanas ou de maior dinamismo. Os países latino-americanos deveriam estabelecer um pacto pela superação da pobreza rural que previsse, no intervalo de quatro ou cinco mandatos presidenciais, equalizar as condições de oferta de um conjunto de equipamentos sociais nos distintos territórios de cada país. Em pleno século XXI, é inconcebível que alguém esteja condenado a ter menos anos de estudo ou menor expectativa de vida apenas por nascer em uma região rural e não nas zonas urbanas mais dinâmicas.

- Temas sensíveis 4: abordagem territorial - Usar uma abordagem territorial não é apenas questão de delimitar uma escala de implementação e gestão de políticas e programas, como se faz usualmente. Território é mais que espaço de aplicação de recursos. É uma unidade que precisa ser mobilizada e transformada. Todos os aspectos mencionados anteriormente reforçam a necessidade de mobilizar investimentos que não se limitam à agricultura ou mesmo aos agricultores. Em vez disso, é necessário mudar o ambiente social, econômico e ecológico em que os agricultores estão inseridos e as ligações rural-urbano. Em outras palavras, há uma dimensão 
de escala (é necessário que as iniciativas se voltem ao ambiente interno e externo às unidades produtivas de agricultores); e, nesta escala mais ampla, deve-se buscar atuar sobre aquele conjunto de interdependências que dão sentido e coesão interna a um território. Superar a pobreza em territórios de expansão da fronteira agrícola exige instrumentos diferentes daqueles usados em territórios de dinâmica antiga e já consolidada. $\mathrm{O}$ mesmo vale para áreas próximas ou distantes de centros urbanos. Ou para territórios com forte ou fraco dinamismo econômico. Territórios importam e precisam ter esta importância traduzida em maior tipificação das iniciativas de acordo com distintas conformações das configurações territoriais de um país (FAVARETO et al., 2015).

- Temas sensíveis 5: as formas de coordenação - Nada do que foi mencionado será possível se não houver atenção especial ao tema das formas de coordenação entre políticas, entre níveis de governo e entre atores públicos e privados. Se os problemas que envolvem as populações rurais têm um caráter multidimensional, é precisamente a capacidade de articular e coordenar esforços empreendidos em diferentes áreas o que representa o maior desafio para abordar esses problemas de forma eficiente. É aqui que têm sido encontradas as maiores dificuldades, como aponta a literatura, para pôr em prática tanto a abordagem territorial como um enfoque relacional das políticas de combate à pobreza e de desenvolvimento rural.

Esses elementos aqui selecionados e sublinhados se baseiam na experiência recente de políticas praticadas em países latino-americanos. Mas há ainda um agravante: nos anos mais recentes nesta segunda década do século, mesmo aquilo que vinha dando certo e levando a uma progressiva melhoria nos indicadores econômicos e sociais entre a população mais pobre da região parece estar perdendo fôlego. Publicado em fins de 2017, o "Relatório Estado da segurança alimentar e nutricional no mundo", publicado pela Organização das Nações Unidas para Agricultura e Alimentação (FAO, 2017) mostra que, após mais de uma década de diminuição, a fome voltou a crescer e afeta, hoje, $11 \%$ da população mundial. São 815 milhões de pessoas, cronicamente, subnutridas. $O$ documento aponta que a situação piorou dramaticamente na África subsaariana e nas porções sudeste e oeste da Ásia, em decorrência de conflitos e fenômenos climáticos que geraram secas prolongadas e enchentes. Para a América Latina, embora com menor gravidade, o quadro não é reconfortante. A estabilização ou redução nos preços das commodities agrícolas posteriormente à crise financeira internacional de 2007/2008 afetou a capacidade fiscal dos Estados nacionais que dependem fortemente deste setor para suas economias e, com isso, 
houve descontinuidade de programas e políticas de combate à pobreza. Somente no Brasil, dados do Instituto Brasileiro de Geografia e Estatística (IBGE, 2017) apontam que, depois de longo período de melhoria nos indicadores, 4,1 milhões de pessoas entraram em condição de pobreza, somente em 2015 (IPEA/Pnud/FJP, 2017), o que deverá repercutir nos níveis de segurança alimentar nos anos subsequentes. Este é o mais claro indicativo de que o enfrentamento da pobreza hoje precisa ser feito em bases diferentes do que vinha ocorrendo nos anos anteriores.

\section{O contexto atual e o que se projeta para o futuro das políticas de combate à pobreza rural na América Latina}

O novo contexto latino-americano de combate à pobreza, nos fins da segunda década do século XXI, é marcado por ao menos três aspectos que tornam as condições de enfrentamento deste tema substantivamente distintas daquelas vistas no período anterior, a primeira década do século, na qual se experimentou significativos progressos. São eles: a) o baixo crescimento econômico e a menor perspectiva de inclusão pelo mercado de trabalho; b) a maior restrição fiscal com menor disponibilidade de recursos para transferências diretas e para ampliação da infraestrutura social; c) o fato de que agora se trata de chegar ao chamado núcleo duro da pobreza. Esta mudança de contexto não representa algo extraordinário. Em vez disso, ela é reveladora de um conjunto de tendências em curso que reposicionam as condições de superar bloqueios históricos da formação social e espacial dos países latino-americanos.

Ao longo da história duas grandes utopias transformadoras guiaram os modelos de Estado e de desenvolvimento: um se apoiava na ideia de especialização baseada em vantagens comparativas, na qual o aproveitamento dos recursos naturais via exportação de matérias primas e produtos primários ocupava lugar de destaque; outra buscava a superação desta condição de exportadores primários via substituição de importações, o que permitiria a industrialização e, com isso, o enriquecimento das sociedades locais. As duas vias estiveram presentes, com diferentes graus de combinação, nas estratégias dos governos progressistas que marcaram o panorama latinoamericano no começo deste século, nos marcos dos quais houve forte redução da pobreza. Mas as transformações do capitalismo internacional mostram que estas duas utopias não podem mais ser mobilizadas em pleno século XXI da mesma forma. A inserção internacional via exportação de commodities tende a condenar os países a uma posição periférica, uma vez que as condições de troca na economia internacional, cada vez mais marcada por alta intensificação tecnológica, dificilmente permitirá que se rompa o fosso que separa as nações mais ricas e industrializadas daquelas dependentes da importação de tecnologias e bens industrializados. Isso, 
mesmo em um contexto em que o crescimento internacional será puxado pela Ásia, compradores dos produtos primários latino-americanos. O arrefecimento da alta das commodities bem o demonstra. Em tal condição, fica difícil pensar em como financiar a modernização da infraestrutura, políticas sociais de combate à pobreza e promoção do bem-estar, ou mesmo a reconversão produtiva. A inserção internacional via exportação de bens de consumo de massa manufaturados encontra uma dupla dificuldade. Por um lado, este espaço foi ocupado por parte dos países asiáticos que, embora não tenham saído na frente, como a Coreia do Sul ou a China, rapidamente alcançaram uma posição de destaque nas exportações industriais, ocupando a posição deixada pelos países mais ricos do mundo, cujas economias agora são puxadas pelo setor financeiro e de serviços. Por outro lado, mesmo uma forte industrialização tende a não gerar impacto semelhante ao visto cinco ou seis décadas atrás na incorporação de trabalho, em função do crescente uso de tecnologias poupadoras do emprego de mão de obra humana. Diante disso, os países latino-americanos estão confrontados com a necessidade de repensar as vias de seu crescimento econômico e de superação de seus bloqueios históricos.

Além destas mudanças econômicas de fundo, as mudanças demográficas do mundo contemporâneo tendem a reforçar tais tendências, uma vez que o crescimento populacional deve se concentrar justamente na África e Ásia, onde estão os maiores contingentes de pessoas pobres. A incorporação destas pessoas na vida econômica e social tende a demandar ainda mais minérios, proteínas e outros gêneros que irão empurrar as economias latino-americanas na direção de ainda maior primarização. Com o agravante de que agora não se terá, possivelmente, a mesma alta de preços verificada na década passada.

Um terceiro campo de mudanças envolve a questão climática. Ela afeta negativamente a condição dos países latino-americanos de, ao menos, duas formas. Mudanças climáticas globais estão alterando as condições de produtividade de outros países, introduzindo novos players no mercado internacional, o que pode afetar a competição com a região. Além disso, essas mesmas mudanças afetam duramente as populações rurais pobres da América Latina, pois alteram a base de recursos naturais de que estas comunidades dependem historicamente para manter seus modos de vida: tem havido uma crescente erosão da biodiversidade em muitas partes da região, menor disponibilidade de recursos hídricos, alteração no regime de chuvas, tudo isso com impactos diretos para os que se encontram sob maior vulnerabilidade. No caso brasileiro o aquecimento e as alterações pluviométricas na Amazônia e no Semiárido, justamente onde se concentra a população rural mais pobre, tende a ser dramática, mesmo em um quadro de redução das emissões de gases estufa. 
Nem tudo se resume a impactos negativos, contudo. Nos três domínios, também se abrem possibilidades, mas que ainda esperam uma retórica adequada para serem mobilizadas e transformadas em estratégias de desenvolvimento. Sob o ângulo das mudanças econômicas, há oportunidades que podem ser aproveitadas. Nunca os índices de escolaridade estiverem tão elevados como agora, apesar de todo o déficit que ainda resta por superar nos países latino-americanos. Em muitas famílias pela primeira vez se supera o analfabetismo. E não é desprezível o contingente de jovens rurais que chegam ao ensino médio e à universidade. Isto significa uma ampliação enorme das possibilidades e da produtividade destas pessoas, para além do acesso a um direito básico e fundamental. Da mesma forma, a conectividade das regiões rurais com as regiões urbanas nunca foi tão expressiva, seja a conectividade física - com extensão das estradas até regiões mais distantes e expansão de veículos de pequeno porte como motocicletas ou pequenos ônibus - seja a conectividade virtual com expansão das redes de energia elétrica, telefonia, telefonia celular e internet -, o que significa toda uma integração de mercados potenciais e acesso à informação que pode ser mais bem aproveitada pelo desenho de políticas de crescimento econômico e de interiorização de investimentos. Para que não pareça mera retórica, muitas redes de supermercado e outras redes comerciais estão se expandindo fortemente em direção a essas regiões interioranas. Sob o ângulo demográfico, em muitos países se estancou o êxodo rural e as grandes metrópoles deixaram de ser o único destino para quem precisa acessar bens e serviços ou o mercado de trabalho, criando novas tramas territoriais, com importância crescente de uma rede interiorizada de cidades médias. Além disso, diminuiu fortemente a taxa de fecundidade e muitos países se encontram hoje na condição que os demógrafos costumam chamar de bônus demográfico, aquela na qual a população em idade ativa supera os que precisam viver na dependência de transferências governamentais. Esta janela demográfica, no entanto, não fica aberta durante muito tempo; portanto, é preciso aproveitá-la. Durante os anos 1970, era comum ouvir a expressão "primeiro é preciso fazer o bolo crescer, para depois distribui-lo”. A estabilização demográfica dos países latino-americanos, prevista para os próximos anos, faz com que pela primeira vez na história o número de pessoas para comer o bolo fique estável, enquanto o bolo tende a continuar a crescer, mesmo que em ritmo mais modesto. Isto traz, mais uma vez, para o centro do debate público o tema da desigualdade - como será distribuído o bolo que continuará a crescer? Sob o ângulo ambiental, por fim, muitos autores como Abramovay $(2012,2017)$ apontam que este século será palco de grande transição nas formas de uso dos recursos naturais. $\mathrm{O}$ forte crescimento das energias renováveis já é um indício disto. Toda a atenção que vem sendo direcionada 
às mudanças climáticas, idem. Esse tipo de transformação irá atingir, ou já vem atingindo, os setores mais tradicionais da economia mundial: é cada vez mais recorrente a busca por formas de produção com menor impacto na agricultura, ou a pesquisa por novos materiais e fontes de energia na indústria de manufaturados. Também avança enormemente a chamada economia criativa ou a economia informacional. Os países latinoamericanos são dotados de trunfos ainda pouco aproveitados, tanto para a geração de energias, como na exploração do potencial da biodiversidade, ou no campo dos chamados serviços ambientais. Aí está uma oportunidade sem igual, mas que ainda vem sendo tratada de forma muito pontual e periférica nas estratégias de desenvolvimento dos países. Mais ainda, tratase de um potencial que pode, justamente, vir a beneficiar os mais pobres, já que é nas regiões rurais que se encontram boa parte desses recursos vitais para a nova economia do século XXI.

\section{A título de conclusão-que desafios se colocam e por que caminhos é possível equacioná-los?}

Como se tentou demonstrar nas seções anteriores, as políticas e os programas de combate à pobreza nos países da América Latina tiveram algumas características que podem ser assim resumidas: a) Apostaram nas transferências condicionadas de renda como a principal e mais rápida via para o alívio da pobreza, e tiveram bastante êxito; b) Trataram de agregar a oferta de bens e serviços públicos destinados a superar privações de capacidades fundamentais como o acesso à educação ou a condições mínimas de saúde, no que também apresentaram resultados expressivos. Pelo lado das dificuldades, também alguns traços são facilmente identificáveis: a) Em muitos casos a superação da condição de pobreza foi tênue e o contexto recente de baixo crescimento econômico e crise fiscal já se traduz em volta do crescimento da fome e da pobreza; b) Embora tenha sido ofertando um amplo leque de políticas, houve frágil coordenação e articulação entre elas, no mais das vezes deixando-se às populações locais que indicassem prioridades em um menu de programas implementados de forma relativamente estanque. Ora, uma política que não é desenhada para ser coordenada dificilmente permite que esta integração seja feita pelos seus beneficiários; c) Há, portanto, enorme fragmentação e baixa adaptabilidade das estratégias de combate à pobreza a contextos específicos. De tudo isso resulta que não se trata, doravante, de somente retomar ou continuar fazendo o que vinha sendo feito até aqui. Inicialmente, pelas insuficiências mencionadas; em segundo lugar, pela mudança de contexto dos anos mais recentes marcados por menor crescimento econômico e crise fiscal; por fim, pelo fato de que o percentual ainda não revertido da pobreza rural representa o chamado núcleo duro da pobreza, para o qual é preciso estabelecer intervenções e ações ainda mais 
robustas. A síntese é clara: é preciso seguir inovando e dar início a uma nova geração de políticas de combate à pobreza, que seja capaz de valorizar os acertos da geração que vem sendo implementada, mas que consiga ir além dela, apoiando-se nos aprendizados gerados pela própria experiência, pelo conhecimento acumulado sobre formas de enfrentamento da pobreza, e pelo entendimento do que muda nos marcos dos anos vindouros. Por onde, então, operar políticas de combate à pobreza na direção da mudança desejada?

Em primeiro lugar, é preciso traduzir estes fragmentos de mudança em uma nova narrativa. Isso implica, antes de tudo, reposicionar o tema da pobreza nas estratégias de desenvolvimento e nas prioridades de alocação do fundo público nos países latino-americanos. Neste reposicionamento, o fundamental é que até hoje a pobreza foi vista como um efeito colateral e momentâneo dos processos de desenvolvimento, algo que poderia ser superado incluindo as pessoas nas tendências econômicas em curso. Algo distintivo, que marca a etapa atual do capitalismo contemporâneo, é que pobreza e desigualdade se tornaram temas intrínsecos e inseparáveis ao próprio estilo predominante de desenvolvimento, tanto em função do alto grau de incorporação de tecnologias poupadoras de trabalho portanto, restritivas à inclusão social -, como em função da financeirização das economias como motor do crescimento, sem a necessidade de investimento na produção e, pois, na incorporação de trabalho. Qual é a consequência desta constatação? Lutar contra a pobreza sem questionar o estilo de desenvolvimento é como enxugar gelo. Em vez das narrativas de desenvolvimento baseadas na especialização apoiada nas vantagens comparativas da produção de commodities ou na simples industrialização, é preciso pensar em modelos por meio dos quais superar condições de privação pode (e deve) ser um dos motores do crescimento econômico dos países latino-americanos.

Essa nova narrativa precisa, no entanto, se traduzir em uma estratégia, sob pena de limitar-se à mera retórica especulativa. E quais devem ser os elementos desta estratégia? Ao menos três aspectos podem ser mobilizados:

a) Enfoque relacional operado sob uma abordagem territorial - $\mathrm{O}$ enfoque relacional tem um duplo sentido: sob o ângulo analítico, ele é uma matriz para um quadro operatório que põe em relação as diversas dimensões da realidade que foram mencionadas buscando as causas existentes entre elas, isto é, a natureza do objeto em questão - nesse caso, a pobreza e a necessidade de sua superação - não pode ser apreendida ou problematizada separando-a das suas relações com outros objetos ou tomando isoladamente algumas de suas dimensões (BACHELARD, 1999); sob o ângulo normativo, tal postura analítica se traduz na necessidade de operar com um conjunto de temas críticos 
a partir do tratamento afirmativo de suas interdependências, entre os quais estão: integração entre investimentos sociais, produtivos e de conservação ambiental; superação da dicotomia rural e urbano; trato afirmativo da diversidade de modos de vida e de características territoriais desde o desenho das políticas, e não somente em sua implementação; indissociabilidade entre enfrentamento da pobreza, da desigualdade e estilos de crescimento econômico.

b) Organizar os elementos do enfoque relacional e de uma abordagem territorial segundo uma visão de longo prazo e baseada em novas vantagens comparativas - Isso significa que as prioridades e metas devam ser pactuadas em uma perspectiva que vá além de um mandato governamental, alcançando um horizonte de 15 a 20 anos. Estas metas deveriam ser estabelecidas de maneira progressiva, de forma que possam ser acompanhadas e monitoradas desde o curto prazo. Elas devem sinalizar um caminho inovador de desenvolvimento, com base não nas velhas vantagens comparativas, como terra e mão de obra barata, mas sim das novas vantagens comparativas, por exemplo, a biodiversidade e a diversidade cultural, o potencial do mercado consumidor interno se devidamente ativado, a disponibilidade de recursos naturais que podem ser usados em bases renováveis, a urbanização descentralizada, os mercados dispostos a remunerar a conservação e a eficiência ambiental.

c) Diminuição das brechas territoriais - Um pacto pela paridade entre regiões e territórios em cada país é fundamental para dar a todos as mesmas condições básicas de superação de suas restrições. No intervalo de uma geração indicadores básicos - como a mortalidade infantil, a expectativa de vida, a escolarização - terão de ser garantidos por meio da dotação de infraestrutura social adequada. Obviamente serviços de maior complexidade somente podem ser ofertados em centros urbanos maiores. Mas todos os territórios deveriam ser objeto desse pacto pela paridade nas condições fundamentais de bem-estar. Aqui, mais uma vez, as características do combate à pobreza podem se transformar em um trunfo em função da economia de custos relativos, já que pode ser mais barato prover certos serviços em zonas rurais do que em zonas urbanas.

Por fim, é preciso responder como operacionalizar esta estratégia. Três aspectos ao menos merecem atenção: 1) Criação de novos marcos legais e institucionais - Como se sabe tão importante quanto as instituições formais são as instituições informais. Se uma nova narrativa sobre a pobreza for partilhada por setores importantes das sociedades latinoamericanas um elemento fundamental do ambiente institucional já terá mudado: as crenças que estão na base das interações humanas. Isso torna 
possível concretizar em marcos legais e em instituições formais elementos basilares da nova narrativa. Um pacto pela paridade entre regiões rurais e urbanas, a dotação e unificação de fundos para o combate à pobreza e a promoção do desenvolvimento, a definição de atribuições de atores públicos e privados na consecução desta estratégia, tudo isso pode ser traduzido em cinco ou seis medidas de alteração dos marcos legais e institucionais com efeito de desencadear outros ajustes em escalas menores. 2) Criar formas de coordenação eficientes e baseadas em formas de governança policêntrica (OSTROM, 2005) - Se há a constatação de que os problemas envolvem múltiplas dimensões, então múltiplas competências precisam ser mobilizadas para enfrentá-los. Estas competências estão dispersas entre diferentes áreas de governo (necessidade de coordenação intersetorial), entre níveis de governo (necessidade de coordenação intergovernamental), entre atores públicos e privados (necessidade de coordenação entre Estado, sociedade e mercado) e entre atores sociais e características do tecido social, econômico e ecológico dos territórios (necessidade de coordenação territorial). Estas formas de coordenação podem se dar com base em diferentes instrumentos segundo a literatura: formas de coordenação em rede, formas de coordenação hierárquica, formas de coordenação baseadas em incentivos (LOTTA; FAVARETO, 2016). 3) Construção de capacidades técnicas e de capacidades políticas coerentes com essa nova visão - Como argumentam Pires e Gomide (2016), processos de inovação em ampla escala em políticas públicas exigem uma conjugação de capacidades técnicas e políticas. Capacidades técnicas são necessárias para produzir as inovações viáveis. Capacidades políticas são necessárias para mobilizar os recursos necessários a massificar essas inovações. Uma, sem a outra, torna-se restritiva. Mas, as capacidades não são neutras. É preciso identificar atores, conhecimentos, habilidades e recursos coerentes com essa nova visão que se pretende implementar.

No início deste artigo, foi apresentada a ideia de que a Agenda 2030 e os ODS representam uma oportunidade para a emergência de novas narrativas, baseadas na interdependência entre o conjunto de temas em torno dos quais se organizam as metas ali expressas. Deve ter ficado evidente, ao longo das páginas anteriores, não somente como o enfrentamento de um tema específico - a pobreza rural - pode operar com estas interdependências, mas também, e mais que isso, que a única forma de lograr resultados mais duradouros e consistentes envolvendo este tema demandam justamente este tipo de esforço. 


\section{Referências}

ABRAMOVAY, R. O futuro das regiões rurais. Porto Alegre: UFRGS, 2003.

ABRAMOVAY, R. Muito além da economia verde. São Paulo: Ed. Abril, 2012.

BACHERLARD, G. Le nouvel esprit scientifique. Paris: PUF, 1999.

BERDEGUÉ, J.; SCHEJTMAN, A. Desarrollo territorial rural. Santiago: Rimisp, 2003.

BERDEGUÉ, J. et al. Explaining Spatial Diversity in Latin American Rural Development: Structures, Institutions, and Coalitions. World Development. V.73, pp. 1-138, September 2015.

BOOTH, C. (1889/1991). Life and labour of the people. Vol. I and II. London, 2003.

CAMPELlO, T. et al. O Brasil Sem Miséria. Brasília: Ministério do Desenvolvimento Social, 2014.

COMISSÃO PARA A MENSURAÇÃO DA PERFORMANCE ECONÔMICA E DO PROGRESSO SOCIAL (CMEPSP). Report by the Commission on the Measurement of Economic Performance and Social Progress. Paris: [s. n.], 2012.

CONSTANZA, R. et al. An overarching goal for the UN Sustainable Development Goals. Situations, v. 5, Issue 4, p. 13-16, 2015.

ELLIS, F. Peasant economics - farm households and agrarian development. Cambridge: Cambridge University Press, 1991.

ESCOBAL, J. \& PONCE, C. Combinando protección social con generación de oportunidades económicas - Una evaluación de los avances del programa Haku Wiñay. Disponível em http://repositorio.minedu.gob.pe/bitstream/ handle/123456789/4731/Combinando\%20protección\%20social\%20 con $\% 20$ generación $\% 20 \mathrm{de} \% 20$ oportunidades $\% 20$ económicas $\% 20$ una $\% 20$ evaluación\%20de\%20los\%20avances\%20del\%20programa\%20Haku\%20Wiñay. pdf?sequence=1\&isAllowed=y. Acessado em: 21 de Agosto de 2016

FOOD AND AGRICULTURE ORGANIZATION OF THE UNITED NATIONS (FAO). The state of food security and nutrition in the world - 2017. Roma: FAO, 2017.

FAVARETO, A. Paradigmas do desenvolvimento rural em questão. São Paulo: Iglu/Fapesp, 2007.

FAVARETO. A. et al. Territórios importam - bases conceituais para uma abordagem relacional do desenvolvimento das regióes rurais ou interioranas no Brasil. Revista Regis/UnB - Revista em Gestão, Inovação e Sustentabilidade. V. 1, N. 1, pp. 14-46. 2015.

FAVARETO, A.; BERDEGUÉ, J. Mudanças globais e locais - implicações para o futuro do enfoque territorial do desenvolvimento rural na América Latina. In: PERAFAN, M. V. et al. Gestão e dinâmicas de desenvolvimento territorial. Curitiba: Ed. CRV, 2018. p. 29-54. 
FERES, J. C.; MANCERO, F. Enfoques para la medición de la pobreza - breve revisión de la literatura. Series Estudios Estatisdicos y Prospectivos, Santiago, n. 4. 2001.

GARCIA, A. B. Desarrollo rural - conceptos, institucionalidad y politicas. Santiago: IICA, 2003.

GEORGE, H. Progress and Poverty: An Inquiry into the Cause of Industrial Depressions and of Increase of Want with Increase of Wealth: The Remedy. New York: [s. n.], 1879.

GRISA, C.; SCHNEIDER, S. (Org.). Políticas públicas e desenvolvimento rural no Brasil. Porto Alegre: UFRGS, 2015.

INTERNATIONAL FUND FOR AGRICULTURAL DEVELOPMENT (IFAD). Rural development report - 2016. Rome: IFAD Publication, 2016.

INSTITUTO BRASILEIRO DE GEOGRAFIA ESTATÍSTICA (IBGE). Pesquisa Nacional por Amostra de Domicílios. 2017.

LAMARCHE, H. L'Agriculture familiale. v. 1 and 2. Paris: L'Harmattan, 1991.

LOTTA, G; FAVARETO, A. Desafios da integração nos novos arranjos institucionais de políticas públicas no Brasil. Revista de Sociologia e Política, v. 24 , n. 57 , p. 49-65, mar. 2016.

MAGNANI, M. O Programa Brasil Sem Miséria e a inclusão produtiva rural lições da experiência brasileira e da literatura internacional. Relatório de Pesquisa. São Bernardo do Campo: UFABC, 2016.

MALDONADO, J. et al. Proteccíon, produccíon, promoción: explorando sinergias entre protección social y fomento productivo rural em América Latina. Bogotá: Uniandes, 2016.

MELO, J. Estratégias de superação da pobreza rural no Brasil recente. Relatório de Pesquisa. São Bernardo do Campo: UFABC, 2017.

NAUDE, A.Y. et al. Evaluación del impacto conjunto de programas de transferencia condicionadas y de apoyo a la producción agrícola sobre la pobreza y la producción de alimentos: el caso de PROSPERA y PROCAMPO en México. Sobre México. Revista de Economía, vol. 3, issue 1, p. 14-33, 2017.

NUSSBAUM, M. Poverty and human functioning: capabilities as fundamental entitlements. In: GRUSKY, D.; KANBUR, R. (Org.). Poverty and ineguality. Stanford: Stanford University Press, 2006.

OSTROM, E. Understanding institutional diversity. Princeton: Princeton University Press.

PIKETTY, T. O capital no século XXI. São Paulo: Ed. Intrínseca, 2015.

PIRES, R. \& GOMIDE, A. Governança e capacidades estatais: uma análise comparativa de programas federais. Revista de Sociologia e Política. vol.24, n.58, pp.121-143.2016.

ROWNTREE, S. Poverty: a study of town life. London: Macmillan and Co., 1901. 
SCOONES, I. Sustainable rural livelihoods: A framework for analysis. IDS Working Paper no 72. Brighton: IDS Publication, 1998.

SEN, A. Poverty and Famines: An Essay on Entitlement and Deprivation. Oxford: Clarendon Press, 1982.

SEN, A. Inequality Reexamined. Oxford: Clarendon Press, 1992.

SEN, A. Development as Freedom. New York: Oxford University Press, 1999.

UNITED NATIONS. The Wye Group Handbook: Statistics on Rural Development and Agricultural Household Income. United Nations Publication: New York, 2013.

UNITED NATIONS. World urbanization prospects - 2014 revision. New York: United Nations Publication, 2014.

UNITED NATIONS. Transforming our world: the 2030 Agenda for Sustainable Development. New York: United Nations Publication, 2015.

UNDP. Human Development Report. New York: Oxford University Press, 1998.

WORLD BANK. World Development Report - Poverty. New York: Oxford University Press, 1990.

WORLD BANK. Rural Development Indicators Handbook. Washington: World Bank Publication, 2000.

WORLD BANK. World Development Report 2008 - Agriculture for Development. Washington: World Bank Publication, 2007.

WORLD BANK \& FAO. Tracking results in agriculture and rural development in less-than-ideal conditions: A sourcebook of indicators for monitoring and evaluation. Joint publication of the Global Donor Platform for Rural Development, FAO \& World Bank. Washington: World Bank Publication, 2008.

Submetido em: $12 / 07 / 2018$

Aceito em: 20/11/2018 


\title{
THE FIGHT AGAINST RURAL POVERTY IN LATIN AMERICA AND THE SUSTAINA- BLE DEVELOPMENT GOALS - THE NEED FOR A RELATIONAL APPROACH
}

\begin{abstract}
At the beginning of the 20th century, Latin American countries achieved a significant reduction in rural poverty. In recent years, statistics from many of these same countries point to a decline of this positive performance and, in some cases, a return to the growth of poverty and hunger. Moreover, the coming years will be marked by a different context, in which the mentioned advances occurred: modest economic growth, greater fiscal restraint. These factors lead to the need to think about the future of initiatives to combat rural poverty beyond the mere continuity or expansion of the actions that were being undertaken. On the other hand, the Agenda 2030 and the Sustainable Development Goals are being launched. It is an ambitious attempt to set concrete goals on a global scale, with each country's commitment to social, economic and environmental issues. This may represent an opportunity for the emergence of new narratives and forms of coordination consistent with a new generation of policies. In this paper, three movements are adopted: a brief resumption of the literature on ways to define poverty and, in particular, rural poverty; a balance of lessons learned from the recent trajectory of policies to combat rural poverty with an emphasis on Latin American reality; and, finally, a reading of current and future trends in contemporary capitalism and how they impact these same policies in the region. In the conclusion, some elements are pointed out around the narratives, the strategies to combat poverty, and the blockages to a greater degree of innovation. The main argument is that, despite the constraints and difficulties, some conditions can be better utilized, and one of the main challenges is the operationalization of a fourth generation of policies and programs, now supported by a relational approach, whose content is presented thrughout the paper.
\end{abstract}

Keywords: Rural poverty. Public policies. Rural development. Sustainable Development Goals.

\section{EL COMBATE A LA POBREZA RURAL EN AMÉRICA LATINA Y LOS OBJETIVOS DEL DESARROLLO SOSTENIBLE - LA NECESIDAD DE UN ENFOQUE RELACIONAL}

\section{Resumen}

A principios del siglo $\mathrm{XX}$, los países de América Latina lograron reducción significativa de la pobreza rural. Sin embargo, en los últimos años, las estadísticas de muchos de estos países señalan una disminución de este desempeño positivo y, en algunos casos, un retorno al crecimiento de la pobreza y el hambre. Además, los próximos años estarán marcados por contexto diferente: crecimiento económico más modesto, mayor restricción fiscal. Estos factores conducen a la necesidad de pensar el futuro de las iniciativas para enfrentar la pobreza rural más allá de la continuidad o expansión de las acciones que se estaban llevando a cabo. Por otro lado, esto se hace en un momento en que se lanza la Agenda 2030 y los Objetivos de Desarrollo Sostenible, ambicioso intento de establecer metas a escala global, con el compromiso de cada país en torno a problemas sociales, económicos y ambientales. Esto puede representar una oportunidad para nuevas narrativas y formas de coordinación consistentes con una nueva generación de políticas. En este paper, se adoptan tres movimientos: breve revisión de la literatura sobre formas de definir la pobreza y, en particular, la pobreza rural; balance de las lecciones aprendidas de la reciente trayectoria de políticas; y, finalmente, una lectura de las tendencias actuales y futuras en el capitalismo contemporáneo y cómo afectan estas mismas políticas en la región. En la conclusión, se señalan elementos en torno a narrativas, estrategias de lucha contra la pobreza y bloqueos a un mayor grado de innovación. El argumento principal es que, a pesar de las limitaciones y dificultades, algunas condiciones pueden utilizarse mejor en la lucha contra la pobreza rural, y uno de los principales desafíos es la operacionalización de una cuarta generación de políticas, ahora respaldados por un enfoque relacional. cuyo contenido se presenta a lo largo del paper.

Palabras clave: Pobreza rural. Políticas públicas. Desarrollo rural. Objetivos de Desarrollo Sostenible. 